This is the final peer-reviewed accepted manuscript of:

Rosita Lapenta, Antonio Buonerba,, Assunta De Nisi, Magda Monari, Alfonso Grassi, Stefano Milione, Carmine Capacchione, Stereorigid OSSO-Type Group 4 Metal Complexes in the Ring-Opening Polymerization of rac-Lactide, Inorganic Chemistry, 2017, 56(6), pp.3447-3458.

The final published version is available online at:

https://doi.org/10.1021/acs.inorgchem.6b02987

Rights / License:

The terms and conditions for the reuse of this version of the manuscript are specified in the publishing policy. For all terms of use and more information see the publisher's website.

This item was downloaded from IRIS Università di Bologna (https://cris.unibo.it/)

When citing, please refer to the published version. 


\title{
Stereorigid OSSO-Type Group 4 Metal Complexes in the Ring- Opening Polymerization of rac-Lactide
}

\author{
Rosita Lapenta, ${ }^{\dagger}$ Antonio Buonerba, ${ }^{\dagger, \ddagger}{ }^{\dagger}$ Assunta De Nisi, ${ }^{\S}$ Magda Monari, ${ }^{\S}$ Alfonso Grassi, ${ }^{\dagger, \dagger}$ \\ Stefano Milione, ${ }^{*}, \dagger, \ddagger$ and Carmine Capacchione ${ }^{\dagger,+}$ \\ ${ }^{\dagger}$ Department of Chemistry and Biology, University of Salerno, via Giovanni Paolo II, 132 Fisciano, I-84084 Salerno, Italy \\ ${ }^{\ddagger}$ Interuniversity Consortium Chemical Reactivity and Catalysis, CIRCC, via Celso Ulpiani 27, 70126 Bari, Italy \\ ${ }^{\S}$ Dipartimento di Chimica G. Ciamician, Alma Mater Studiorum, Università di Bologna, via Selmi 2, Bologna, Italy
}

\begin{abstract}
The synthesis and characterization of a series of group 4 metal complexes of general formula $\left\{\mathrm{OSSO}_{\mathrm{X}}\right\} \mathrm{M}(\mathrm{OR})_{2}\left(\mathrm{X}=\mathrm{R}={ }^{t} \mathrm{Bu}, \mathrm{M}=\right.$ $\mathrm{Zr}$ (1); $\mathrm{X}=$ cumyl, $\mathrm{M}=\mathrm{Zr}, \mathrm{R}={ }^{t} \mathrm{Bu}$ (2); $\mathrm{X}=$ cumyl, $\mathrm{M}=\mathrm{Ti}, \mathrm{R}={ }^{i} \operatorname{Pr}(4) ; \mathrm{X}$ = cumyl, $\left.\mathrm{M}=\mathrm{Hf}, \mathrm{R}={ }^{t} \mathrm{Bu}(\mathbf{5})\right)$ and $\left\{\mathrm{OSSO}_{\mathrm{X}}\right\}_{2} \mathrm{Zr}(\mathrm{X}=\mathrm{Cl}(\mathbf{3}))$ supported by $o$-phenylene-bridged bis(phenolato) ligands ( OSSO $_{\mathrm{tBu}}-H=6,6^{\prime}-((1,2-$ phenylenebis(sulfanediyl))bis(methylene))bis(2,4-di-tert-butyphenol); OS$\mathrm{SO}_{\text {Cum }}-H=6,6^{\prime}-((1,2$-phenylenebis(sulfanediyl $))$ bis(methylene $\left.)\right)$ bis $(2,4$ bis(2-phenylpropan-2-yl)phenol); $\mathrm{OSSO}_{\mathrm{Cl}^{-}} \mathrm{H}=6,6^{\prime}$-((1,2-phenylenebis(sulfanediyl) )bis(methylene))bis(2,4-dichlorophenol)) are described herein. Complexes $1-5$ were readily obtained by $\sigma$-bond metathesis reactions between the proligand and the appropriate homoleptic metal precursor. The reaction with $\mathrm{OSSO}_{\mathrm{Cl}}$ yielded the bis-ligand complex $\left\{\mathrm{OSSO}_{\mathrm{Cl}}\right\}_{2} \mathrm{Zr}$ (3) regardless of the $\mathrm{OSSO}_{\mathrm{Cl}^{-}} \mathrm{H} / \mathrm{Zr}\left(\mathrm{O}^{t} \mathrm{Bu}\right)_{4}$ molar ratio or experimental

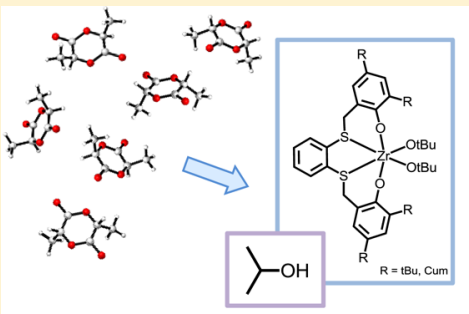

$\checkmark$ efficient ROP of rac-lactide

$\checkmark$ activated monomer mechanism

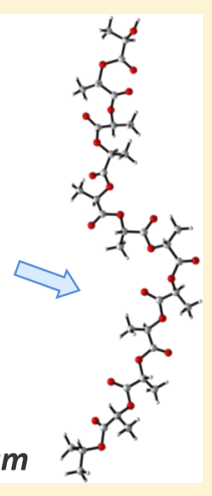
conditions. All complexes were characterized in solution using NMR spectroscopy and, in the case of 2 , by single-crystal X-ray diffraction experiments. These complexes show a fac-fac ligand wrapping and a cis relationship between the other two monodentate ligands; zirconium and hafnium complexes 1-3 and 5 are configurationally stable, whereas titanium complex $\mathbf{4}$ is fluxional in solution at room temperature. The complexes tested in the ring-opening polymerization (ROP) of racemic-lactide showed, except in the case of 3, moderate rates and good levels of polymerization control. Upon addition of an exogenous alcohol (isopropyl alcohol or tert-butyl alcohol) efficient binary catalytic systems were achieved. Polymerizations were well-controlled, as testified by the linear growth of the molecular weight as polymerization proceeded, narrow polydispersity indices, and molecular weights close to those expected on the basis of added alcohol amounts. Experimental and theoretical evidence is provided that ROP reactions operate according to an activated monomer mechanism.
\end{abstract}

\section{INTRODUCTION}

An issue of economic and environmental concern is the replacement of petroleum-based plastics with green and degradable alternatives. ${ }^{1}$ Produced from starch and composted or recycled after utilization, polylacic acid (PLA) has already found extensive applications both as a commodity plastic (e.g., packaging, fibers) and as an engineering polymer (e.g., for the development of scaffolds for tissue fabrication or controlled drug release systems). ${ }^{2}$ One of the most common synthetic route for its preparation is the ring-opening polymerization (ROP) of lactide (LA). ${ }^{3}$ This reaction can be efficiently promoted by a large variety of discrete Lewis acidic metal alkoxide complexes. ${ }^{4}$ Among these, group 4 metal complexes present several advantages such as low toxicity, good control over polymerization reactions, and good activity and stability even in the presence of protic impurities. ${ }^{5}$ Typically, these catalysts are based on octahedral complexes featuring bi- or tetradentate phenoxo-type chelating ligands. Due to the hard
Lewis acidity of the group 4 metal, phenoxo donors have been paired with relatively hard nitrogen-based donors. ${ }^{5}$ One noteworthy case is the series of zirconium and hafnium complexes bearing a 2,2'-bipyrrolidine-derived salan ligand; these complexes represent a rare example of initiators able to yield highly isotactic enriched polymers. ${ }^{6}$

The use of soft second-row atoms as neutral donors to saturate the coordination sphere of the oxophilic metal center was shown to be advantageous for the catalytic activity, as they can regulate the Lewis acidic nature of the metal center and consequently the catalytic reactivity of the coordination complex. ${ }^{5}$ Indeed, tetradentate dithiodiolate supported group 4 complexes, reported by Kol et al., resulted in extremely active initiators for lactide polymerization: the $\mathrm{Hf}$ complex was able to convert in melt 300 equiv of monomer after $1 \mathrm{~min}^{7}$ Another 
interesting class of complexes is that of group 4 complexes bearing tetradentate (OSSO)-type bis(phenolato) ligands, extensively studied by Okuda and co-workers. ${ }^{8}$ These complexes efficiently promote the ring-opening polymerization of lactide in a controlled manner. In particular, in the polymerization of meso-lactide, OSSO-titanium complexes afforded syndiotactic poly(meso-LA) while OSSO-zirconium complexes produced heterotactically enriched PLA. ${ }^{8}$ More recently, Kol and Okuda introduced the tetradentate dianionic iminethiobis(phenolate) $\{$ ONSO $\}$-type ligands and their group 4 metal complexes. They initially found that the stereoselectivity is determined by the fluxionality of the complex: the rigid complexes afforded isotactic PLA, whereas the fluxional complexes afforded heterotactic PLA. ${ }^{9}$ Subsequently, with a new group of phenylene ONSO ligands, they have found that the tacticity is determined by the nature of the substituents on the phenolate and not by fluxionality. ${ }^{10}$

As part of our interest in the ring-opening polymerization of cyclic esters promoted by group 4 metal complexes, we have recently reported on a series of group 4 metal complexes bearing two bidentate thioetherphenolate ligands that showed good catalytic performance with regard to the activity and control over the polymerization process. ${ }^{11}$ In an effort to further examine the structure-activity relationships affecting the reactivity and the stereoselectivity of group 4 initiators, we have developed new catalysts for lactide polymerization and obtained more insight into the parameters that control their activity. In this paper we report on the synthesis and structural characterization of a series of group 4 metal complexes supported by $o$-phenylene-bridged bis(phenolato) ligands and their use in the ROP of rac-lactide. Herein we demonstrate that the presence of a phenylene bridge between the two phenoxo units results in a rigid coordination environment around the metal center with significant consequences on the catalytic activity.

\section{RESULTS AND DISCUSSION}

Synthesis and Characterization. The OSSO ligands used in this work were prepared by nucleophilic substitution of the suitable 2-(bromomethyl)phenol with benzene-1,2-dithiol using dry THF as solvent, as reported in Scheme $1 .{ }^{12}$ In order to

Scheme 1. Synthetic Route to Complexes 1-5

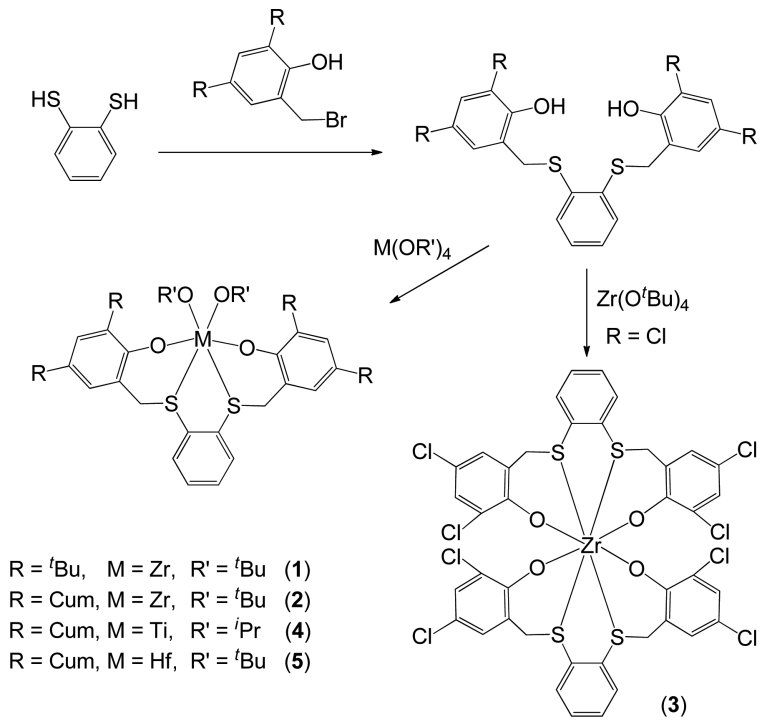

evaluate the role of the steric or electronic properties of the ligands on the coordination and reactivity of the corresponding group 4 complexes, we prepared three different ligands, in which the $\mathrm{R}$ substituent on the phenoxo donor is a tert-butyl group, a cumyl group, or a chlorine atom $\left(\mathrm{OSSO}_{\mathrm{tBu}}-\mathrm{H}=6,6^{\prime}\right.$ ((1,2-phenylenebis(sulfanediyl))bis(methylene))bis(2,4-di-tertbutylphenol); $\mathrm{OSSO}_{\mathrm{Cum}}-\mathrm{H}=6,6^{\prime}-((1,2$-phenylenebis(sulfanediyl))bis(methylene))bis(2,4- bis(2-phenylpropan-2yl)phenol); $\mathrm{OSSO}_{\mathrm{Cl}}-\mathrm{H}=6,6^{\prime}-((1,2$-phenylenebis(sulfanediyl))bis(methylene))bis(2,4-dichlorophenol)).

These ligands were purified by recrystallization or column chromatography and fully characterized using NMR, elemental analysis, MS, and FT-IR (see the Supporting Information). Recrystallization of $\mathrm{OSSO}_{\mathrm{Cum}}-\mathrm{H}$ from toluene afforded crystals suitable for X-ray analysis (Figure 1).

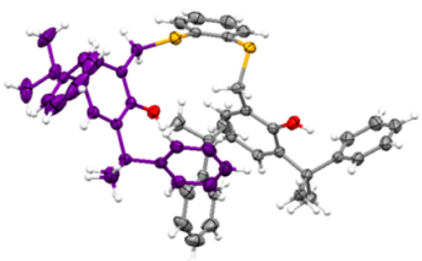

Figure 1. Molecular structure of $\mathrm{OSSO}_{\mathrm{Cum}}-\mathrm{H}$, in which the $\mathrm{C}$ atoms of one of the two side arms of the thiophenoxo unit are depicted in purple for sake of clarity (thermal ellipsoids at the $30 \%$ probability level).

Complexes $\left\{\mathrm{OSSO}_{\mathrm{X}}\right\} \mathrm{M}(\mathrm{OR})_{2}\left(\mathrm{X}=\mathrm{R}={ }^{t} \mathrm{Bu}, \mathrm{M}=\mathrm{Zr}(\mathbf{1}) ; \mathrm{X}\right.$ = cumyl, $\mathrm{M}=\mathrm{Zr}, \mathrm{R}={ }^{t} \mathrm{Bu}(2) ; \mathrm{X}=$ cumyl, $\mathrm{M}=\mathrm{Ti}, \mathrm{R}={ }^{i} \operatorname{Pr}(4)$; $\mathrm{X}=$ cumyl, $\left.\mathrm{M}=\mathrm{Hf}, \mathrm{R}={ }^{t} \mathrm{Bu}(5)\right)$ were prepared by $\sigma$-bond metathesis reactions between the proligand and the appropriate homoleptic metal precursor enabling alcohol elimination, in toluene solution at room temperature, as reported in Scheme 1. ${ }^{1} \mathrm{H}$ NMR monitoring showed that the reactions are fast and quantitative in a few minutes. In all reactions, except that with OSSO $_{\mathrm{Cl}}-\mathrm{H}$, the desired complex of general formula $\left\{\mathrm{OSSO}_{\mathrm{X}}\right\}$. $\mathrm{M}(\mathrm{OR})_{2}$ was obtained with no contamination of any side products. Attempts to prepare the parent zirconium complex $\left\{\mathrm{OSSO}_{\mathrm{Cl}}\right\} \mathrm{Zr}\left(\mathrm{O}^{t} \mathrm{Bu}\right)_{2}$ by reacting $\mathrm{Zr}\left(\mathrm{O}^{t} \mathrm{Bu}\right)_{4}$ with $\mathrm{OSSO}_{\mathrm{Cl}}$ yielded the homoleptic complex $\left\{\mathrm{OSSO}_{\mathrm{Cl}}\right\}_{2} \mathrm{Zr}$ (3) regardless of the $\mathrm{OSSO}_{\mathrm{Cl}}-\mathrm{H} / \mathrm{Zr}\left(\mathrm{O}^{t} \mathrm{Bu}\right)_{4}$ molar ratio or experimental conditions. Reversing the order of addition of the reactants, changing the solvent (toluene or dichloromethane), or lowering the reaction temperature did not affect the outcome of the reaction. Comproportionation reaction attempts between$\left\{\mathrm{OSSO}_{\mathrm{Cl}}\right\}_{2} \mathrm{Zr}$ and $\mathrm{Zr}\left(\mathrm{O}^{\mathrm{t}} \mathrm{Bu}\right)_{4}$ did not lead to the heteroleptic complex. The different product outcome obtained with OSSO $_{\mathrm{Cl}}-\mathrm{H}$ could be due to the higher acidity of this ligand in addition to the lower steric encumbrance provided by the chloro substituents. The homoleptic complex $\left\{\mathrm{OSSO}_{\mathrm{Cl}}\right\}_{2} \mathrm{Zr}$ was prepared in pure form by reacting $\mathrm{Zr}\left(\mathrm{O}^{t} \mathrm{Bu}\right)_{4}$ with 2 equiv of the ligand precursors.

The wrapping of linear tetradentate ligands around octahedral metal centers may produce three configurational isomers, indicated as mer-mer (trans), fac-fac (cis- $\alpha$ ), and fac-mer (cis- $\beta$ ), showing the corresponding $C_{2 v}, C_{2}$, and $C_{1}$ symmetries. The last two structures are chiral-at-metal isomers and exist as two stereoisomers $(\Lambda$ and $\Delta)$. In the ${ }^{1} \mathrm{H}$ NMR spectrum of $\mathbf{1}$, the methylene protons displayed the typical $A B$ pattern for diastereotopic protons in a $C_{2}$-symmetric environment, indicating a $f a c-f a c$ ligand wrapping and cis relationship between 
the other two monodentate ligands. Complex 1 was configurationally stable; as a matter of fact, the heating of a toluene solution up to $100{ }^{\circ} \mathrm{C}$ did not induce the coalescence of the resonances as expected for a fast $\Delta-\Lambda$ enantiomer interconversion but only resulted in a line broadening of the signals. This behavior is consistent with the presence of a rigid phenylene bridge between the sulfur atoms. Similar tetradentate [OSSO] zirconium complexes with an ethylene bridge and a 65-6 array of chelate rings are rigid at room temperature but become fluxional upon warming at $100{ }^{\circ} \mathrm{C}$, with a coalescence temperature of $85{ }^{\circ} \mathrm{C} .{ }^{13}$ The existence of fluxional behavior in the slow-exchange regime for $\mathbf{1}$ was investigated by ${ }^{1} \mathrm{H}-{ }^{1} \mathrm{H}$ EXSY experiments at $60{ }^{\circ} \mathrm{C}$. As shown in Figure 2, positive

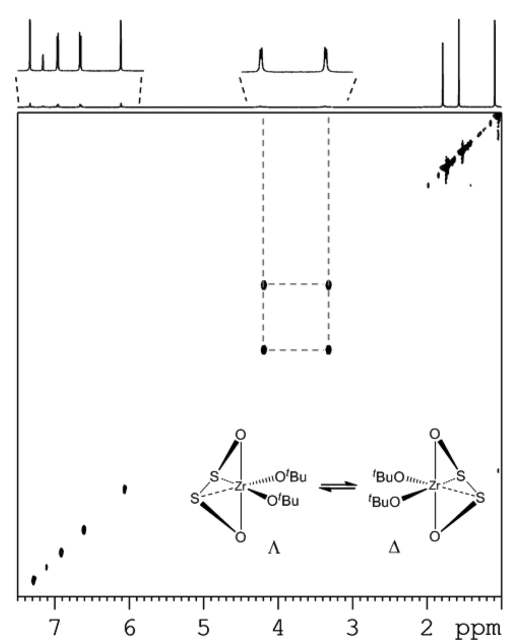

Figure 2. ${ }^{1} \mathrm{H}-{ }^{1} \mathrm{H}$ EXSY spectrum of $\left(\mathrm{OSSO}_{\mathrm{tBu}}\right) \mathrm{Zr}\left(\mathrm{O}^{t} \mathrm{Bu}\right)_{2}\left(\mathrm{C}_{6} \mathrm{D}_{6}, 60\right.$ ${ }^{\circ} \mathrm{C}$, mixing time $\left.0.400 \mathrm{~s}, 600 \mathrm{MHz}\right)$. Exchange of the protons of the methylene group is evidenced $\left(k_{\text {exchange }}=0.27 \mathrm{~s}^{-1}\right)$.

cross-peaks correlating the signals of methylene groups were clearly detected. The intensity of these peaks allowed us to evaluate the rate constant for the $\Delta-\Lambda$ interconversion as 0.27 $\mathrm{s}^{-1}$, corresponding to a free energy of activation of $20.4 \mathrm{kcal}$ $\mathrm{mol}^{-1}$

Single isomers of $C_{2}$ symmetry were also observed in the cases of zirconium and hafnium complexes 2 and 5 . In these cases, the symmetry of the complexes is also reflected in the spin patterns displayed by the methyl protons of the ortho and para cumyl groups. As a matter of fact, the methyl groups of each cumyl substituent are diastereotopic and give rise to two singlets (for each cumyl group). The presence of the sterically hindered cumyl groups on the ligand skeleton increased the rigidity of the metal complexes; the rate constants for the $\Delta-\Lambda$ interconversion obtained from the EXSY experiments were 0.05 $\mathrm{s}^{-1}$ for both 2 and 5 , corresponding to a free energy of activation of $21.6 \mathrm{kcal} \mathrm{mol}^{-1}$.

The ${ }^{1} \mathrm{H}$ NMR spectrum of complex 3 was in agreement with a highly symmetric structure: it featured two doublets for the eight phenoxo $\mathrm{CH}$ protons (at 7.04 and $5.88 \mathrm{ppm}$ ) and two multiplets for the eight protons of the two phenyl bridges (at 6.59 and $6.74 \mathrm{ppm}$ ). The methylene protons displayed the expected $A B$ pattern. It is worth noting that one of the two doublets was shifted downfield, appearing at $5.59 \mathrm{ppm}$. The inspection of the minimum-energy structure obtained through DFT calculations revealed that the protons of the $\mathrm{S}-\mathrm{CH}_{2}$ group are in two different environments: one proton is close to the phenoxo group of the other ligand (2.46 $\AA$ ), and the other points toward the outside of the coordination sphere (see Figure 3). GIAO NMR calculations indicated that the first proton should be much more deshielded than the other; it is reasonable to assume that both isotropic and anisotropic effects contribute to the prominent deshielding of this proton.

At room temperature, the ${ }^{1} \mathrm{H}$ NMR spectrum of the titanium complex 4 displayed broad resonances for the $\mathrm{S}-\mathrm{CH}_{2}$ protons and for the methyl protons of the ortho cumyl groups and isopropoxide groups, suggesting a fluxional $C_{2}$-symmetric structure. Even though complex $\mathbf{4}$ carries bulky cumyl groups, it is substantially more flexible than the analogous zirconium complex 2 or the less encumbered complex 1; this behavior may be ascribed to the weakening of the $S-$ metal bonds that has to take place in this complex due to the weaker interaction between the soft sulfur atom and the hard titanium ion in comparison to the stronger soft-S-soft-Zr interaction. At low temperature, the resonances appeared sharp and well resolved and the whole ${ }^{1} \mathrm{H}$ NMR spectrum was consistent with a complex featuring a rigid $C_{2}$-symmetric structure. VT NMR analysis showed that the coalescence of the signals occurs at 0 ${ }^{\circ} \mathrm{C}$. Kinetic parameters were calculated using line-shape analysis of the ${ }^{1} \mathrm{H}$ NMR data measured over the temperature range -40 to $30{ }^{\circ} \mathrm{C}$ in dichloromethane- $d_{2} ;{ }^{1} \mathrm{H}$ NMR spectra and calculated exchange rates are shown in the Supporting Information. The free energy of activation for the fluxional processes was calculated to be $\Delta G^{\ddagger}=13.4 \pm 0.1 \mathrm{kcal} \mathrm{mol}^{-1}$ at $293 \mathrm{~K}$. The activation parameters were $\Delta H^{\ddagger}=11.9 \pm 0.3 \mathrm{kcal}$ $\mathrm{mol}^{-1}$ and $\Delta S^{\ddagger}=-5 \pm 1 \mathrm{cal} \mathrm{mol}^{-1} \mathrm{~K}^{-1}$.

The X-ray single-crystal structure of the complex $\left(\mathrm{OSSO}_{\mathrm{Cum}}\right) \mathrm{Zr}\left(\mathrm{O}^{t} \mathrm{Bu}\right)_{2}$ (Figure 4) shows that in the solid state the $C_{2}$ symmetry is maintained if the methyl groups of the two tert-butoxy ligands are not considered. As expected for [OSSO]- and [ONNO]-type complexes, ${ }^{14}$ the $\mathrm{Zr}$ atom possesses an octahedral environment in which the [OSSO] ligand adopts a fac-fac wrapping coordination mode with the
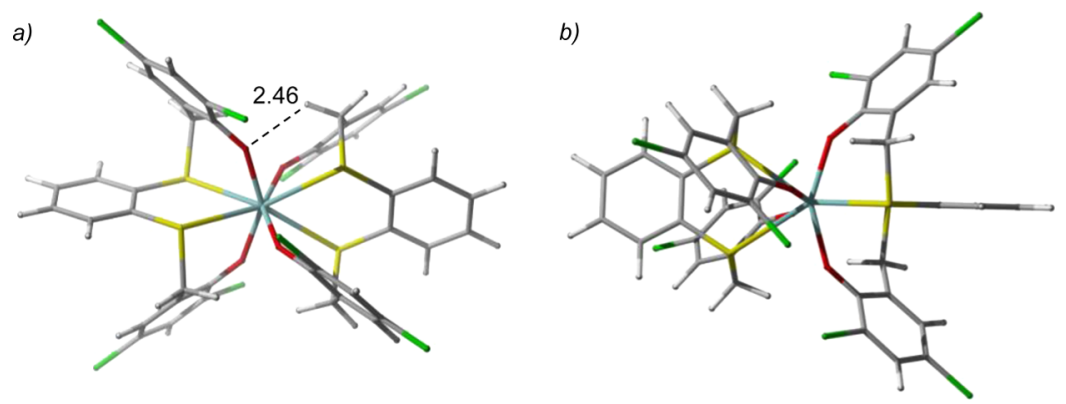

Figure 3. Top (a) and front views (b) of the minimum-energy structure for complex 3. The distance is given in $\AA$. 

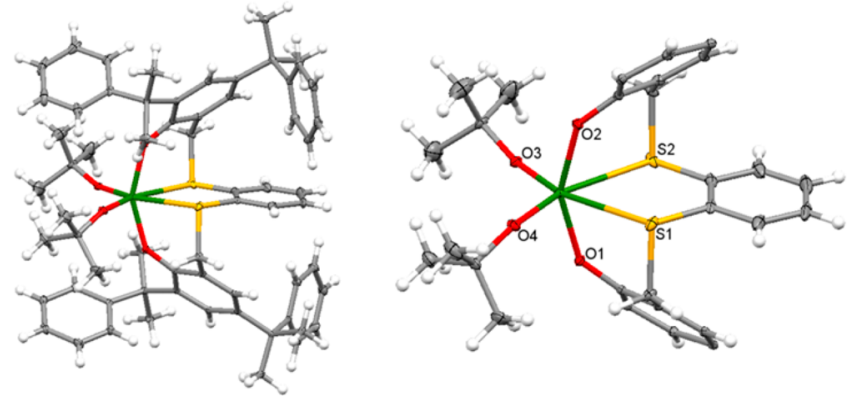

Figure 4. ORTEP drawing of $\left(\mathrm{OSSO}_{\mathrm{Cum}}\right) \mathrm{Zr}\left(\mathrm{O}^{t} \mathrm{Bu}\right)_{2}$ showing on the left the complete structure and highlighting on the right the $C_{2}$ symmetry of the complex upon removal of the external groups (thermal ellipsoids are at the $30 \%$ probability level). Selected bond lengths $(\AA)$ and angles (deg): Zr-S1 2.8704(5), Zr-S2 2.8797(5), $\mathrm{Zr}-\mathrm{O} 1$ 2.0309(14), Zr-O2 2.0380(14), Zr-O3 1.9263(14), Zr-O4 1.9420(15); S1-Zr1-S2 70.928(18).

tert-butyloxy ligands in mutually cis positions. The metal atom is involved in a perfectly planar disulfometallacyclopentane ring with an $\mathrm{S} 1-\mathrm{Zr}-\mathrm{S} 2$ bite angle of $70.93(2)^{\circ}$, whereas in the two previously reported structures of [OSSO]-Zr-OtBu complexes $^{13,14}$ the $\mathrm{Zr}$ atom forms with the [OSSO] ligand puckered five-membered rings with wider $\mathrm{S} 1-\mathrm{Zr}-\mathrm{S} 2$ bite angles of $73.80(2)$ and $73.84(5)^{\circ}$. Interestingly, not only the two phenolate groups in trans positions are pulled away from the tert-butoxy ligands $\left(\mathrm{O} 1-\mathrm{Zr}-\mathrm{O} 2152.56(4)^{\circ}\right)$ but also two terminal cumyl groups of the OSSO ligand point toward the inner thiocathecolate ring from opposite directions. The $\mathrm{Zr}-\mathrm{S}$ distances (Zr-S1 2.8703(4) $\AA$ and $\mathrm{Zr}-\mathrm{S} 2$ 2.8797(4) $\AA$ ) are significantly longer than those found in the other two similar $\left[(\mathrm{OSSO}) \mathrm{Zr}(\mathrm{O}-\mathrm{tBu})_{2}\right]$ complexes $(\mathrm{Zr}-\mathrm{S} 2.828(1)$ and $2.8279(7)$ and $2.8485(7) \AA),{ }^{13,14}$ presumably in order to alleviate a worse steric congestion around the $\mathrm{Zr}$ atom. The $\mathrm{Zr}-\mathrm{O}$ (alkoxy) and $\mathrm{Zr}-\mathrm{O}$ (OSSO) distances fall in the range normally found for these kinds of complexes. ${ }^{14}$

Ring-Opening Polymerization of rac-Lactide. Complexes 1-5 were evaluated as catalysts for the ROP of raclactide. The screening was carried out in toluene solution at 100 ${ }^{\circ} \mathrm{C}$ with an initiator to monomer ratio of 100 . The main results are reported in Table 1.

The reactions proceeded slowly reaching high monomer conversions in about 1 day, for both zirconium complexes 1 and 2; consequently, low turnover frequencies were obtained $\left(\mathrm{TOF}=3.7\right.$ and $\left.4.0 \mathrm{~h}^{-1}\right)$. As homoleptic group 4 metal complexes containing two (OSSO)-type ligands were found to be active in the ring-opening polymerization of lactide monomers, ${ }^{15}$ we also tested complex 3 . Even after extended polymerization times, complex 3 resulted inactive. When the metal was changed from zirconium in $\mathbf{2}$ to hafnium in $\mathbf{5}$, the polymerization activity remained unchanged; differently, when the metal was changed from zirconium in $\mathbf{2}$ to titanium in $\mathbf{4}$, the polymerization activity drastically decreased and satisfactory monomer conversion was achieved only after 3 days.

In the case of the polymerization promoted by 2 , aliquots of the product mixture were withdrawn from the reactor at given reaction times, quenched with wet $\mathrm{CDCl}_{3}$, and analyzed by ${ }^{1} \mathrm{H}$ NMR spectroscopy and GPC measurements. This procedure permitted us to get an insight into the reaction kinetics and into the evolution of the molecular weight of the polymers with the conversion. At $100{ }^{\circ} \mathrm{C}$, an induction period of about $6 \mathrm{~h}$ was observed; after this time the polymerization proceeds with the expected first-order kinetics in monomer concentration: the semilogarithmic plot was linear with a slope of $0.147 \pm 0.008$ $\mathrm{h}^{-1}$ (Figure 5a). At lower polymerization temperature $\left(80^{\circ} \mathrm{C}\right)$, the catalytic activity decreased $\left(k_{\text {obs }}=0.0371 \pm 0.0009 \mathrm{~h}^{-1}\right.$; see Figure $5 \mathrm{a}$ ) and a longer induction period (about $15 \mathrm{~h}$ ) was registered. The delay for the beginning of the reaction is probably related to the genesis of the real catalytically active species for the polymerization. To clarify this initiation/ activation process, the reaction between 2 and rac-lactide was followed by ${ }^{1} \mathrm{H}$ NMR spectroscopy (2:rac-lactide = 1:1, room temperature, $\left.\mathrm{C}_{6} \mathrm{D}_{6}\right)$. Initially the resonances of the reagents were clearly discerned but, over time, the signals of 2 slowly decreased in intensity and a very complicated new pattern of signals emerged in the spectrum. Notwithstanding different efforts, any attempt to identify the product mixture was inconclusive.

The molecular weight distributions of the polymers were monomodal and narrow in all cases; moreover, a good match was observed between the experimental number-average molecular weights $\left(M_{n}(\exp )\right)$ and the theoretical weights estimated assuming the growth of one polymer chain per metal initiator. In the case of the polymers obtained by 4 , the $M_{\mathrm{n}}(\exp )$ values were close to the theoretical molecular weights calculated by hypothesizing the growth of two polymer chains per Ti initiator. An analogous comportment was encountered in the polymerization of L-lactide promoted by other group 4 metal complexes with bi- or tetradentate bis(phenolato) ligands. ${ }^{8 a, 11,16}$ In the case of the polymerization promoted by 2, we verified that the experimental number-average molecular weight grows linearly with the monomer conversion (Figure $5 b)$.

The end-capping groups were recognized by NMR and ESIMS spectroscopy. In the ${ }^{1} \mathrm{H}$ NMR spectrum of a PLA sample obtained by 2 , the tert-butoxycarbonyl ending group was easily identified by a minor resonance at $\delta 1.46\left(\mathrm{CDCl}_{3}\right.$; see Figure S16 in the Supporting Information). In the corresponding ESI-

Table 1. Ring-Opening Polymerization of rac-Lactide

\begin{tabular}{|c|c|c|c|c|c|c|c|}
\hline entry $^{a}$ & initiator & $t / \mathrm{h}$ & conversn $/ \%^{b}$ & $\mathrm{TOF} / \mathrm{h}^{-1 c}$ & $M_{\mathrm{n}}(\mathrm{th})^{d}$ & $M_{\mathrm{n}}(\operatorname{expt})^{e}$ & $\mathrm{PDI}^{e}$ \\
\hline 1 & 1 & 24 & 88 & 3.7 & 12.7 & 14.0 & 1.12 \\
\hline 2 & 2 & 24 & 96 & 4.0 & 13.8 & 17.1 & 1.12 \\
\hline 3 & 3 & 24 & 0 & & & & \\
\hline 4 & 4 & 72 & 90 & 1.3 & $6.5^{f}$ & 6.3 & 1.13 \\
\hline 5 & 5 & 24 & 94 & 3.9 & 13.5 & 15.4 & 1.23 \\
\hline
\end{tabular}

${ }^{a}$ All reactions were carried out in $2.4 \mathrm{~mL}$ of toluene; $[\mathrm{I}]_{0}=5.0 \mathrm{mM},[\mathrm{LA}]=0.52 \mathrm{M},[\mathrm{LA}] /[\mathrm{I}]_{0}=100$, and $T=100{ }^{\circ} \mathrm{C} .{ }^{b} \mathrm{Molecular}$ conversion determined by ${ }^{1} \mathrm{H}$ NMR spectroscopy $\left(\mathrm{CDCl}_{3}, 298 \mathrm{~K}\right) .{ }^{c} \mathrm{TOF}=\mathrm{mol}_{\mathrm{LA}} /\left(\mathrm{mol}_{\mathrm{I}} \mathrm{h}\right) .{ }^{d}$ Calculated molecular weight using $\mathrm{M}_{\mathrm{n}}(\mathrm{th})\left(\mathrm{kg} \mathrm{mol}^{-1}\right)=(144.13$ $\times\left([\mathrm{LA}]_{0} /[\mathrm{I}]_{0}\right) \times(\mathrm{LA}$ conversion $\left.)\right) / 1000 .{ }^{e}$ Experimental molecular weight $M_{\mathrm{n}}(\mathrm{expt})\left(\mathrm{kg} \mathrm{mol}^{-1}\right)$ and polydispersity $(\mathrm{PDI})$ determined by GPC in THF using polystyrene standards and corrected using the factor $0.58 .{ }^{f_{M}}(\mathrm{th})\left(\mathrm{kg} \mathrm{mol}^{-1}\right)=\left(144.13 \times\left([\mathrm{LA}]_{0} /[2 \times \mathrm{I}]_{0}\right) \times(\mathrm{LA}\right.$ conversion $\left.)\right) / 1000$. 

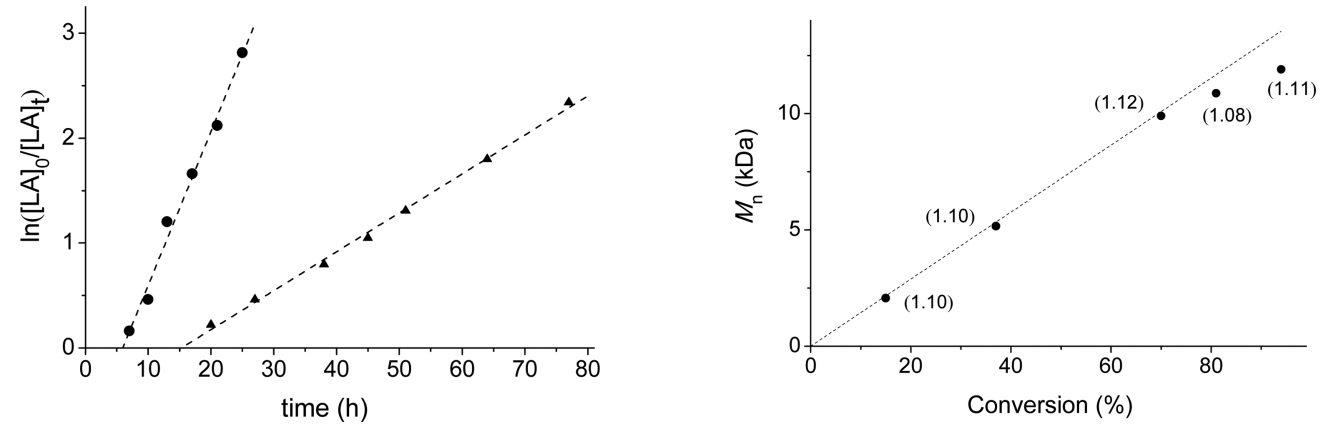

Figure 5. (a) Pseudo-first-order kinetic plots for ROP of rac-LA by 2 at $100{ }^{\circ} \mathrm{C}(\boldsymbol{\bullet})$ and $80{ }^{\circ} \mathrm{C}(\boldsymbol{\Delta})\left(k_{\text {obs }}\left(100{ }^{\circ} \mathrm{C}\right)=0.147 \pm 0.008 \mathrm{~h}^{-1}, R^{2}=0.986\right.$; $\left.k_{\text {obs }}\left(80^{\circ} \mathrm{C}\right)=0.0371 \pm 0.0009 \mathrm{~h}^{-1}, R^{2}=0.996\right)$. (b) Plot of number-averaged molecular weights $M_{\mathrm{n}}($ expt) (dots) vs monomer conversion (\%) with theoretical $M_{\mathrm{n}}(\mathrm{th})$ (dashed line) using 2 as an initiator at $100{ }^{\circ} \mathrm{C}, M_{\mathrm{w}} / M_{\mathrm{n}}$ values are given in parentheses. Conditions: $[\mathrm{I}]_{0}=5.0 \mathrm{mM} ;[\mathrm{LA}]_{0} /[\mathrm{I}]_{0}=$ 100 , toluene as solvent.

Table 2. Ring-Opening Polymerization of rac-Lactide in the Presence of Exogenous Alcohol

\begin{tabular}{|c|c|c|c|c|c|c|c|c|c|c|}
\hline entry $^{a}$ & initiator & temp $/{ }^{\circ} \mathrm{C}$ & alcohol & $t / \mathrm{h}$ & conversn $/ \%^{b}$ & $\mathrm{TOF} / \mathrm{h}^{-1 c}$ & $M_{\mathrm{n}}(\mathrm{th})^{d}$ & $M_{\mathrm{n}}(\text { expt })^{e}$ & $\mathrm{PDI}^{e}$ & $P_{\mathrm{r}}^{f}$ \\
\hline 1 & 1 & 100 & $i \mathrm{PrOH}$ & 5 & 80 & $1.6 \times 10^{1}$ & 2.3 & 3.8 & 1.10 & 0.51 \\
\hline 2 & 2 & 100 & $i \mathrm{PrOH}$ & 0.5 & 94 & $1.9 \times 10^{2}$ & 2.7 & 2.3 & 1.16 & 0.55 \\
\hline 3 & 2 & 80 & $i \mathrm{PrOH}$ & 1.5 & 97 & $6.5 \times 10^{1}$ & 2.8 & 1.9 & 1.10 & 0.56 \\
\hline 4 & 2 & 50 & $i \mathrm{PrOH}$ & 45 & 71 & 1.6 & 2.0 & 2.1 & 1.10 & 0.57 \\
\hline 5 & 3 & 100 & $i \mathrm{PrOH}$ & 24 & 72 & 3.0 & 2.1 & 2.1 & 1.19 & 0.57 \\
\hline 6 & 4 & 100 & $i \mathrm{PrOH}$ & 2 & 92 & $4.6 \times 10^{1}$ & 2.6 & 1.3 & 1.11 & 0.52 \\
\hline 7 & 5 & 100 & $i \mathrm{PrOH}$ & 0.5 & 95 & $1.9 \times 10^{2}$ & 2.7 & 1.8 & 1.20 & 0.58 \\
\hline 8 & 2 & 100 & $t \mathrm{BuOH}$ & 0.17 & 95 & $5.6 \times 10^{2}$ & 2.7 & 4.8 & 1.21 & 0.58 \\
\hline 9 & 2 & 80 & $t \mathrm{BuOH}$ & 0.33 & 94 & $2.8 \times 10^{2}$ & 2.7 & 3.8 & 1.10 & 0.66 \\
\hline 10 & 2 & 50 & $t \mathrm{BuOH}$ & 24 & 95 & 4.0 & 2.7 & 4.7 & 1.09 & 0.66 \\
\hline
\end{tabular}

${ }^{a}$ All reactions were carried out in $2.4 \mathrm{~mL}$ of toluene; $[\mathrm{I}]_{0}=5.0 \mathrm{mM},[\mathrm{LA}]=0.52 \mathrm{M},[\mathrm{ROH}]=25.0 \mathrm{mM}$, and $[\mathrm{LA}]_{0}:[\mathrm{I}]_{0}:[\mathrm{ROH}]_{0}=100: 1: 5$. ${ }^{b}$ Molecular conversion determined by ${ }^{1} \mathrm{H}$ NMR spectroscopy $\left(\mathrm{CDCl}_{3}, 298 \mathrm{~K}\right) .{ }^{c} \mathrm{TOF}=\operatorname{mol}_{\mathrm{LA}} /\left(\mathrm{mol}_{\mathrm{I}} \mathrm{h}\right) .{ }^{d}$ Calculated molecular weight using $M_{\mathrm{n}}(\mathrm{th})$ $\left(\mathrm{kg} \mathrm{mol}^{-1}\right)=\left(144.13 \times\left([\mathrm{LA}]_{0} /[\mathrm{ROH}]_{0}\right) \times(\right.$ LA conversion $\left.)\right) / 1000 .{ }^{e}$ Experimental molecular weight $M_{\mathrm{n}}($ expt $)\left(\mathrm{kg} \mathrm{mol}^{-1}\right)$ and polydispersity (PDI) determined by GPC in THF using polystyrene standards and corrected using the factor $0.58 .{ }^{f}$ Probability of racemic linkages as determined by homodecoupled ${ }^{1} \mathrm{H}$ NMR spectroscopy.
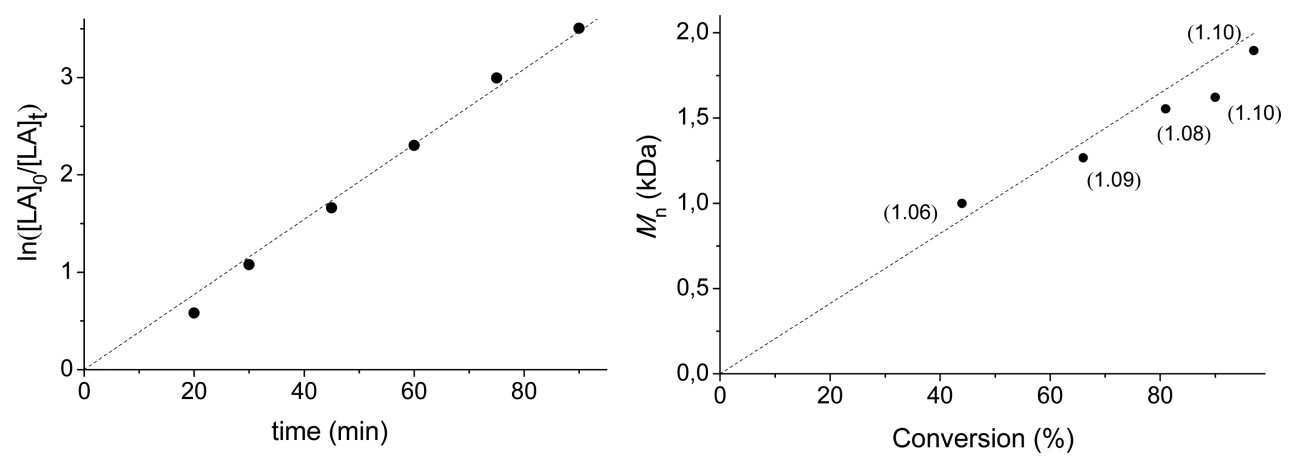

Figure 6. (a) Pseudo-first-order kinetic plot for ROP of $\mathrm{rac}$-LA by $2 / \mathrm{iPrOH}\left(k_{\mathrm{obs}}=0.0386 \pm 0.0008 \mathrm{~min}^{-1}=2.32 \pm 0.05 \mathrm{~h}^{-1} ; R^{2}=0.998\right)$. (b) Plot of number-averaged molecular weights $M_{\mathrm{n}}$ (expt) (dots) vs monomer conversion (\%) with theoretical $M_{\mathrm{n}}\left(\right.$ th) (dash line) using $2 / \mathrm{iPrOH}$. $M_{\mathrm{w}} / M_{\mathrm{n}}$ values are given in parentheses. Conditions: $[\mathrm{I}]_{0}=5.0 \mathrm{mM} ;[\mathrm{LA}]_{0} /[\mathrm{I}]_{0}=100 ;[\mathrm{iPrOH}] /[\mathrm{I}]=5$; toluene as solvent; $\mathrm{T}=80{ }^{\circ} \mathrm{C}$.

MS spectrum, the principal series of peaks was attributed to linear even-membered and odd-membered oligomers endcapped with hydroxy and tert-butoxide groups: i.e., $\mathrm{H}-$ $\left[\mathrm{OCH}\left(\mathrm{CH}_{3}\right) \mathrm{C}(=\mathrm{O})\right]_{n}-\mathrm{OtBu}$. The presence of these groups implies that the reaction starts with the attack of the tert-butoxy group of the initiator to the monomer and stops because of the hydrolysis of the metal-alkoxide bond, as typically occurs in ring-opening polymerizations proceeding with a coordination/ insertion mechanism. A second series of peaks was observed and attributed to the presence of cyclic oligomers. This, together with the mass-to-mass peak increment of $72 \mathrm{Da}$, indicates that intra- and inter-transesterification processes are operative during the propagation step.

The microstructure of the PLAs was determined by homonuclear decoupled ${ }^{1} \mathrm{H}$ NMR spectra of the methine region. ${ }^{17}$ Disappointingly, in spite of the stereorigidity of the metal complexes used as initiators, the PLAs by 1-5 were atactic $\left(P_{\mathrm{r}} \approx 0.50-0.55\right)$.

Polymerization of rac-LA in the Presence of Exogenous Alcohol. In the ROP of cyclic esters, the addition of alcohol has a beneficial effect on the catalytic performance. ${ }^{18}$ Under "immortal" polymerization conditions, alcohols operate as chain transfer agents with metal catalysts, leading to the 
growth of one $\mathrm{H}-[\mathrm{PLA}]-\mathrm{OR}$ polymer chain per added $\mathrm{ROH}$. Thus, the productivity of the catalyst is optimized and the content of the metal traces in the polymeric product is minimized. With the aim of improving our catalytic results, we tested the performances of $\mathbf{1 - 5}$ in the presence of 2-propanol; the main results are reported in Table 2 .

To our surprise, the polymerization rates were significantly affected by the addition of isopropyl alcohol. As a matter of fact, in toluene solution at $100{ }^{\circ} \mathrm{C}$, high monomer conversions were reached in $5 \mathrm{~h}$ for 1 . The catalytic activity was not hampered by the steric encumbrance of the ortho substituents on the phenoxo groups; indeed, high monomer conversions were reached in $1 / 2 \mathrm{~h}$ for 2 and 5 . The turnover frequencies increased 50-fold $\left(\right.$ TOF $=1.9 \times 10^{2} \mathrm{~h}^{-1}$ ). An analogous comportment was already observed in the polymerization of $\mathrm{L}$ lactide initiated by other group 4 metal complexes featuring bidentate thioetherphenolate ligands. ${ }^{11}$ In the case of the titanium complex $\mathbf{4}$ high monomer conversion was achieved in $2 \mathrm{~h}$. In the presence of isopropyl alcohol also the coordinatively saturated complex $\mathbf{3}$ was effective for rac-lactide polymerization, leading to good monomer conversion in $24 \mathrm{~h}$. Also in these cases, the PLA showed neither heterotactic nor isotactic enrichment. At lower reaction temperature $\left(80\right.$ or $\left.50{ }^{\circ} \mathrm{C}\right)$, the catalytic activity decreased but the $P_{\mathrm{r}}$ values remained unaffected (entries 3 and 4, Table 2).

The reaction promoted by $2 / \mathrm{iPrOH}$ was monitored at $80{ }^{\circ} \mathrm{C}$ by analyzing the reaction mixtures taken from the reactor at precise intervals. The monomer conversion obeyed a first-order kinetics, with immediate initiation; the propagation rate constant was $2.32 \pm 0.05 \mathrm{~h}^{-1}$ (Figure 6a).

A linear relationship between experimental molecular weights and monomer conversion and values comparable to the theoretical values estimated assuming the growth of one macromolecular chain per added alcohol equivalent were observed (Figure 6b). In addition, the PDI values were relatively narrow and constant during the polymerization process. In the ${ }^{1} \mathrm{H}$ NMR spectrum of the PLA obtained in entry 2 of Table 2, minor resonances due to end groups were clearly detected. In detail, a heptet at $5.08 \mathrm{ppm}$ and a false triplet at $1.25 \mathrm{ppm}$ were attributed to isopropyl ester end groups, while a broad multiplet at $4.35 \mathrm{ppm}$ and a doublet at $1.69 \mathrm{ppm}$ were attributed to the $-\mathrm{CH}\left(\mathrm{CH}_{3}\right) \mathrm{OH}$ end group (see Figure S17 in the Supporting Information). Analysis of the ESI-MS spectrum confirmed the presence of these end groups. The mass-to-mass peak increment of $72 \mathrm{Da}$ and the presence of cyclic oligomers indicated that the polymerization process is affected by intra- and intermolecular side reactions.

To further investigate the catalytic performances of 2 , the effect of the monomer to initiator molar ratio was explored. The catalytic system $2 / \mathrm{iPrOH}$ was able to polymerize $\mathrm{rac}$-LA at a high loading of monomer. The number-average molecular weights of the obtained PLA grew linearly with the monomer to initiator ratio, ranging from 100 to 1000 ; at the same time the molecular weight distributions are almost constant (see Figure 7). The gradient of the line of least-squares best fit is $19.8 \mathrm{~g} \mathrm{~mol}^{-1}\left(R^{2}=0.986\right)$; this value is lower than the expected value of $28.8 \mathrm{~g} \mathrm{~mol}^{-1}$ for one chain growing per added alcohol equivalent. The mismatch indicates a loss of control over the polymerization provided by this system at a high monomer to initiator ratio.

With the aim to get more insights into the mechanism of the polymerization carried out in the presence of alcohol, we monitored the reaction of this class of complexes with isopropyl

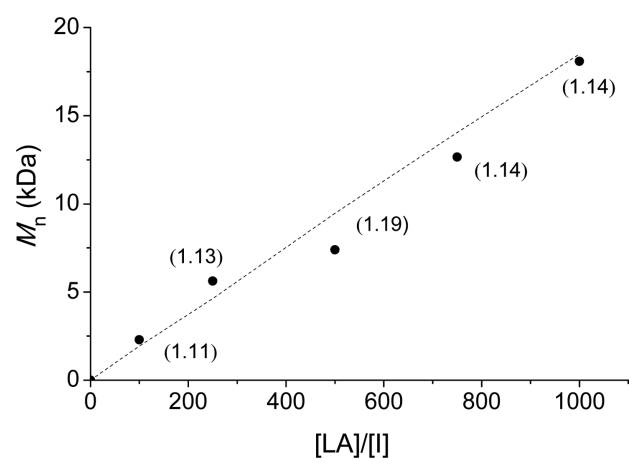

Figure 7. Plot of number-averaged molecular weights $M_{\mathrm{n}}$ (expt) (dots) vs monomer to initiator ratio with theoretical $M_{\mathrm{n}}$ (th) (dashed line) using $2 / \mathrm{iPrOH} . M_{\mathrm{w}} / M_{\mathrm{n}}$ values are given in parentheses. Conditions: $[\mathrm{I}]_{0}=5.0 \mathrm{mM}$; $[\mathrm{iPrOH}] /[\mathrm{I}]=5$; toluene as solvent; $T=100{ }^{\circ} \mathrm{C}$.

alcohol. We used complex 1 for our studies, as its ${ }^{1} \mathrm{H}$ NMR spectrum is quite simple. The treatment of 1 with 5 equiv of isopropyl alcohol at room temperature in $\mathrm{C}_{6} \mathrm{D}_{6}$ resulted in the rapid substitution of the tert-butoxide ligands bonded to the zirconium atom, yielding the isopropoxide derivative $\left\{\mathrm{OSSO}_{\mathrm{tBu}}\right\} \mathrm{Zr}(\mathrm{O} i \mathrm{Pr})_{2}(6)$ in nearly quantitative yield. A low amount $(10 \%)$ of the ligand $\mathrm{OSSO}_{\mathrm{tBu}}-\mathrm{H}$ was initially discerned among the product mixture, over the course of $60 \mathrm{~min}$, complex 6 remained unreacted, proving that 6 is stable in the presence of the residual isopropyl alcohol and the produced tert-butyl alcohol. The substitution of the alkoxide starting group on the zirconium atom may affect the rate of the initiation but, in our opinion, it hardly explains the increase of the polymerization rate observed in the presence of isopropyl alcohol. To clarify the role of the starting group, we thought to use tert-butyl alcohol $(\mathrm{tBuOH})$ as an exogenous alcohol. First we checked the stability of $\mathbf{1}$ in the presence of $\mathrm{tBuOH}$ excess. The corresponding ${ }^{1} \mathrm{H}$ NMR spectrum was the sum of the NMR spectra of 1 and $\mathrm{tBuOH}$ taken separately $(1: \mathrm{tBuOH}=1: 2$, toluene- $\left.d_{8}, 60{ }^{\circ} \mathrm{C}\right) .2 \mathrm{D}{ }^{1} \mathrm{H}-{ }^{1} \mathrm{H}$ EXSY experiment $\left(\tau_{\mathrm{m}}=1.800\right.$ s) proved the exchange between tert-butyl alcohol and the tertbutoxy group bound of the metal center. The corresponding rate constant was determined by the intensities of the positive cross peaks; the obtained value of $1.0 \times 10^{-3} \mathrm{~s}^{-1}$ indicated that the ligand exchange is particularly slow. Addition of tert-butyl alcohol to the polymerization reaction promoted by 2 had a strong influence on the polymerization rate; as matter of fact, high monomer conversions were achieved in about 10 mins, a third of the time required using isopropyl alcohol to achieve similar conversions (compare entries 2 and 8 or entries 3 and 9). At $80{ }^{\circ} \mathrm{C}$, the monomer conversion follows first-order kinetics with respect to monomer concentration; the apparent propagation rate constant was $7.8 \pm 1.2 \mathrm{~h}^{-1}$. The molecular weight increased regularly with monomer concentration and showed a good match with the theoretical values estimated assuming the growth of one macromolecular chain per added alcohol equivalent. The PDI values were narrow and constant during the course of polymerization. The ${ }^{1} \mathrm{H}$ NMR and ESI analysis of the PLA samples confirmed the presence of $\mathrm{tBuOC}(=\mathrm{O})-$ and $-\mathrm{CH}\left(\mathrm{CH}_{3}\right) \mathrm{OH}$ as end groups.

The dependence of the polymerization rate on the nature of the exogenous alcohol and the absence of a reaction between 1 and $t \mathrm{BuOH}$ clearly indicate that the ROP reaction promoted by this class of complexes in the presence of an exogenous alcohol proceeds via the "activated monomer" mechanism. ${ }^{19}$ In other worlds, polymerization proceeds through the attack of the 
alcohol (the initial added alcohol or a HO-terminated PLA chain) to the LA monomer activated by an interaction with the metal complex. Generally, in this polymerization scheme the metal complex acts as a Lewis acid catalyst.

DFT Calculations on the Ring-Opening Reaction. In order to shed more light on the "activated monomer" mechanism underlying the ring opening of lactide, a DFT investigation was carried out. To save computational resources, the structural elements that are nonessential for the mechanistic understanding of the reaction were removed: i.e., the bulky alkyl substituents were removed from the ligand, lactide was modeled with glycolide (GL), and isopropyl alcohol was modeled with methanol. At first we tried to understand in which way the three components of our catalytic system $\{\mathrm{OSSO}\} \mathrm{Zr}(\mathrm{OMe})_{2} / \mathrm{MeOH} / \mathrm{GL}$ interact with each other. We started trying to locate a coordination adduct between GL and the zirconium model complex, but all our attempts met with failure. The scan of the energy surface corresponding to the approach of the monomer to the zirconium atom of the complex is reported in Figure 8; it discloses a small relative

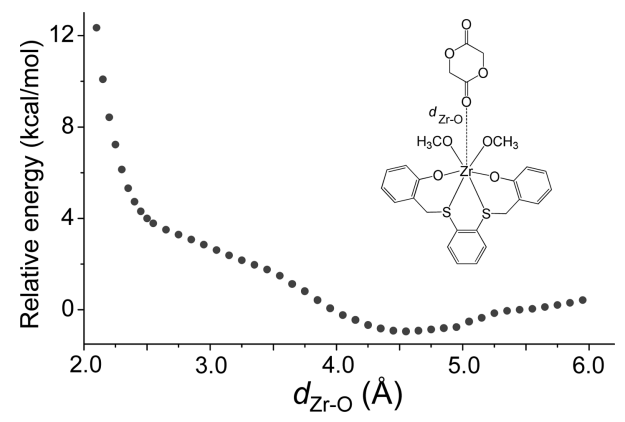

Figure 8. Potential energy surface scan for the approach of glycolide to the metal center of the zirconium model complex.

minimum only when the exocyclic oxygen atom of the monomer was located at about $4.5 \AA$ from the metal center. Relaxed optimization of the system $\{\mathrm{OSSO}\} \mathrm{Zr}(\mathrm{OMe})_{2} / \mathrm{GL}$ converged to a stable adduct in which the oxygen atom of GL was located at $4.56 \AA$ from the metal center; this distance is not compatible with the coordination of the monomer to the metal center. A close inspection of the adduct revealed the presence of short $\mathrm{H} \cdots \mathrm{O}$ distances, suggesting that GL and $\{\mathrm{OSSO}\} \mathrm{Zr}-$ $(\mathrm{OMe})_{2}$ are bonded though hydrogen-bond contacts. The binding energy $\left(\Delta H_{\text {bind }}\right)$, calculated as the difference between the enthalpy of the $\{\mathrm{OSSO}\} \mathrm{Zr}(\mathrm{OMe})_{2} / \mathrm{GL}$ adduct and the sum of the enthalpies of the metal complex $\{\mathrm{OSSO}\} \mathrm{Zr}(\mathrm{OMe})_{2}$ and GL is $-0.6 \mathrm{kcal} / \mathrm{mol}$.

Subsequently we searched for a stable coordination adduct between the zirconium model complex and methanol. In this case we succeeded in locating a stable heptacoordinated heteroleptic derivative $\left(A^{0}\right)$ whose minimum energy structure is reported in Figure 9. In $A^{0}$ the oxygen atom of the alcohol was located $2.41 \AA$ from the metal center and the hydrogen atom of the $\mathrm{OH}$ group points toward one of the two alcoholate ligands $\left(d_{\mathrm{H} \cdots \mathrm{O}}=1.78 \AA\right)$. The enthalpy of coordination was $-4.7 \mathrm{kcal} / \mathrm{mol}$.

Therefore, we tried to coordinate the monomer to the metal

center of this derivative, but our attempts were unsuccessful. We only found the adduct $A$ between $A^{0}$ and glycolide, in which the exocyclic oxygen atom of the monomer was hydrogen-bonded with the $\mathrm{OH}$ group of the coordinated methanol $\left(d_{\mathrm{H} \cdots \mathrm{O}}=1.79 \AA\right)$; the minimum energy structure of $A$
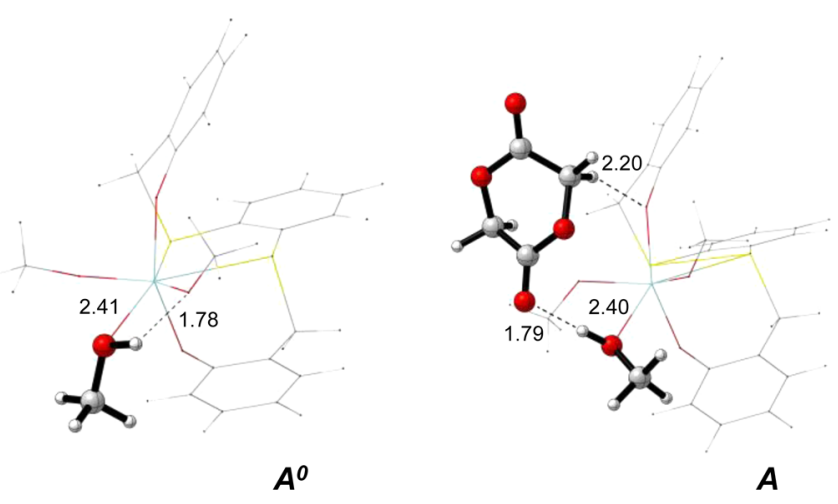

Figure 9. Minimun energy structures of adducts $A^{0}$ and $A$. Distances are given in $\AA$.

is reported in Figure 9. The enthalpy change for the formation for $\boldsymbol{A}$ was $-1.1 \mathrm{kcal} / \mathrm{mol}$. We used this structure as a starting point for the DFT calculations; the free energy profile is displayed in Figure 10, and the transition states are shown in

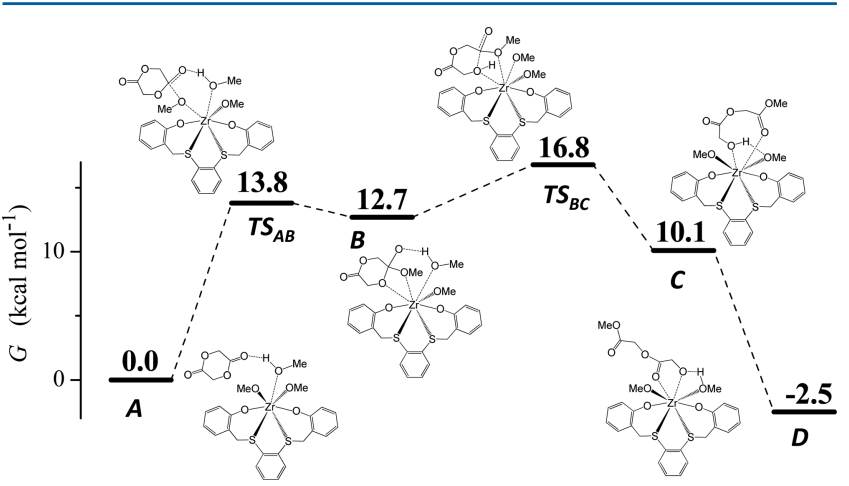

Figure 10. Computed free energy surface for the ring-opening polymerization of glycolide promoted by the zirconium model complex and methanol. The free energies are given in $\mathrm{kcal} / \mathrm{mol}$.

Figure 11. The reaction starts with the nucleophilic attack of one of the methoxy ligands to the $\mathrm{C}=\mathrm{O}$ group of the hydrogen-bonded monomer leading to the intermediate $\boldsymbol{B}$. In this species the hydrogen bond between the $\mathrm{OH}$ group and the exocyclic oxygen atom of the monomer is strengthened as the hydrogen atom moves closer to the oxygen atom $\left(d_{\mathrm{O} \cdots \mathrm{H}}=1.58\right.$ $\AA$ ), while the endocyclic oxygen atom of the monomer is in

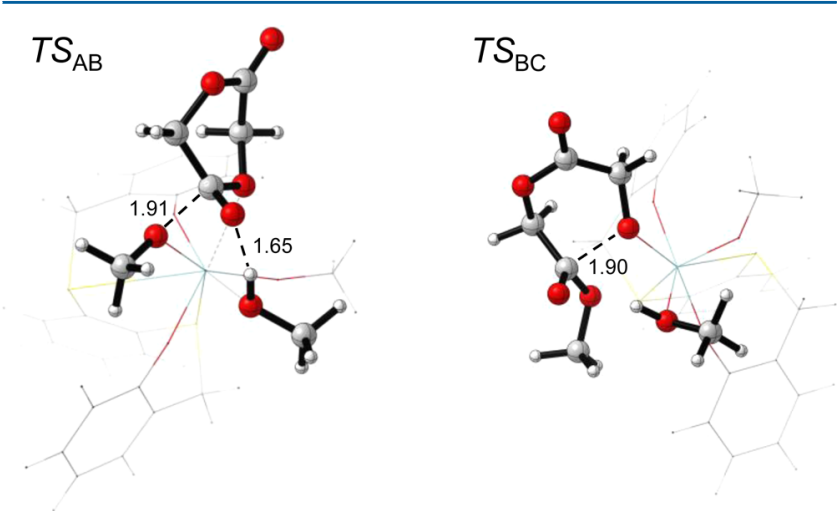

Figure 11. Transition states for the nucleophilic attack $\left(T S_{\mathrm{AB}}\right)$ and ring opening $\left(T S_{\mathrm{BC}}\right)$ for the zirconium model complex. Distances are given in Å. 
close proximity to the metal center $\left(d_{\mathrm{O} \cdots \mathrm{Zr}}=2.37 \AA\right)$. This step requires overcoming a barrier of $13.8 \mathrm{kcal} / \mathrm{mol}$; this is a quite high barrier, which is however consistent with the temperature of $100{ }^{\circ} \mathrm{C}$ needed experimentally to achieve high activity. At the transition state $T S_{A B}$, the rehybridization of $\mathrm{C}=\mathrm{O}$ from $\mathrm{sp}^{2}$ toward $\mathrm{sp}^{3}$ is evidenced by the slight elongation of the $\mathrm{C}=\mathrm{O}_{e}$ bond. Following the intrinsic reaction coordinate, intermediate $\boldsymbol{B}$ goes forward to the ring-opening step, surmounting an activation barrier of $4.1 \mathrm{kcal} / \mathrm{mol}$ (relative to intermediate $B$ ). In $T S_{B C}$ the proton migration was induced from the exocyclic oxygen atom to the endocyclic oxygen atom. In the product $C$, the monomer was fully opened $\left(\mathrm{C}_{\mathrm{C}=\mathrm{O}}-\mathrm{O}_{i}=3.76 \AA\right)$. Transfer back of the hydrogen atom to the methoxy ligand and isomerization of the growing chain leads to the intermediate $\boldsymbol{D}$. The formation of $\boldsymbol{D}$ featuring an heterocyclic $\mathrm{Zr}$ lactate makes ring opening of glycolide thermodynamically feasible $(-2.5 \mathrm{kcal}$ $\left.\mathrm{mol}^{-1}\right)$.

It is worth noting that, in the mechanism we disclose here, the alcohol does not externally attack the metal-bound monomer, as is generally assumed in the "activated monomer" mechanism. ${ }^{19}$ In our case the nucleophilic attack at the carbon atom of the $\mathrm{C}=\mathrm{O}$ is carried out by the alkoxide ligand bonded to the metal center, which is coherent with the higher nucleophilic character of the alkoxide anion in comparison to the neutral alcohol. Moreover, the alcohol behaves as a source of protons stabilizing the negatively charged intermediates that form after the nucleophilic attack to the ester group and facilitating the subsequent ring-opening step.

\section{CONCLUSIONS}

A series of group 4 metal complexes featuring o-phenylenebridged bis(phenolato) ligands were successfully prepared and fully characterized by NMR spectroscopy. In one case X-ray crystallographic data were obtained and confirmed the fac-fac ligand wrapping around the metal center. The zirconium and hafnium complexes were configurationally stable; the barriers for the configuration inversion of the metal complexes, obtained from EXSY experiments, were proportional to the steric encumbrance of the alkyl groups on the phenolate rings. The titanium complex $\mathbf{4}$ was substantially more flexible than the analogous complexes, probably because of the weaker interaction between the soft sulfur atom and the hard titanium ion.

In the ring-opening polymerization of rac-lactide, all complexes, except the homoleptic derivative 3, showed moderate activities and effective control over the polymerization process. As matter of fact, linear growths of molecular weight versus the monomer conversion and narrow molecular weight distributions were obtained. Although end groups analysis indicated that the reaction is started by the transfer of the metal-bound alkoxide group bound to the monomer, the presence of an induction period at the beginning of the reaction suggests that the initiators undergo a drastic change before the polymerization can start.

In the presence of exogenous alcohol, all complexes displayed higher polymerization rates. Moreover, the linear dependence of molecular weight versus lactide conversion, the narrow polydispersity indices, and the molecular weights close to those expected on the basis of added alcohol equivalents indicate that effective conditions for "immortal" polymerizations were attained. The lack of reactivity of these complexes with exogenous alcohol has induced us to propose that these compounds operate by an activated monomer mechanism. This conclusion was also supported by DFT studies, which failed to locate the coordination adduct between the monomer and the zirconium model complex. It is well established that in the coordination-insertion mechanism this step is a prerequisite for the insertion of the monomer in the metal-alkoxide bond. Moreover, a plausible reaction path for the activated monomer mechanism was proposed.

\section{EXPERIMENTAL SECTION}

Materials and Methods. All preparations and subsequent manipulations of air- and/or water-sensitive compounds were carried

Table 3. Crystal Data and Structure Refinement Details for OSSO $_{\mathrm{Cum}}-\mathrm{H}$ and $\left(\mathrm{OSSO}_{\mathrm{Cum}}\right) \mathrm{Zr}\left(\mathrm{O}^{\mathrm{t}} \mathrm{Bu}\right)_{2} \cdot \mathrm{C}_{7} \mathrm{H}_{8}$

\begin{tabular}{|c|c|c|}
\hline & OSSO $_{\mathrm{Cum}}-\mathrm{H}$ & $\underset{\mathrm{C}_{7} \mathrm{H}_{8}}{\left(\mathrm{OSSO}_{\mathrm{Cum}}\right) \mathrm{Zr}\left(\mathrm{O}^{\mathrm{t}} \mathrm{Bu}\right)_{2} .}$ \\
\hline empirical formula & $\mathrm{C}_{56} \mathrm{H}_{58} \mathrm{O}_{2} \mathrm{~S}_{2}$ & $\mathrm{C}_{64} \mathrm{H}_{74} \mathrm{O}_{4} \mathrm{~S}_{2} \mathrm{Zr} \cdot \mathrm{C}_{7} \mathrm{H}_{8}$ \\
\hline formula wt & 827.14 & 1154.70 \\
\hline temp, K & $296(2)$ & $100(2)$ \\
\hline cryst syst & triclinic & triclinic \\
\hline space group & $P \overline{1}$ & $P \overline{1}$ \\
\hline$a, \AA$ & $12.7680(7)$ & $12.2584(8)$ \\
\hline$b, \AA$ & $13.8560(8)$ & $13.0961(8)$ \\
\hline$c, \AA$ & $14.8684(8)$ & $20.3390(13)$ \\
\hline$\alpha, \operatorname{deg}$ & $68.673(3)$ & $97.925(3)$ \\
\hline$\beta, \operatorname{deg}$ & $76.025(3)$ & $101.671(3)$ \\
\hline$\gamma, \operatorname{deg}$ & $75.630(3)$ & $98.390(3)$ \\
\hline cell volume, $\AA^{3}$ & $2340.1(2)$ & $3115.9(3)$ \\
\hline$Z$ & 2 & 2 \\
\hline$\rho_{\mathcal{c}} \mathrm{Mg} \mathrm{m}^{-3}$ & 1.174 & 1.231 \\
\hline$\mu(\mathrm{Mo} \mathrm{K} \alpha), \mathrm{mm}^{-1}$ & 0.155 & 0.291 \\
\hline$F(000)$ & 884 & 1224 \\
\hline cryst size, mm & $0.30 \times 0.25 \times 0.15$ & $0.20 \times 0.20 \times 0.15$ \\
\hline$\theta$ limits, deg & 1.491 to 25.126 & 1.038 to 24.927 \\
\hline $\begin{array}{l}\text { no. of collected, unique rflns } \\
\left(R_{\text {int }}\right)\end{array}$ & $\begin{array}{l}34094 / 8256 \\
(0.0286)\end{array}$ & $43666 / 10765(0.0318)$ \\
\hline goodness of fit on $F^{2}$ & 0.995 & 1.067 \\
\hline $\operatorname{R} 1(F),{ }^{a}{ }^{a R 2} 2\left(F^{2}\right)(I>2 \sigma(I))^{b}$ & $0.0407,0.100$ & $0.0270,0.0675$ \\
\hline $\begin{array}{l}\text { largest diff peak and } \\
\text { hole, e } \AA^{-3}\end{array}$ & $0.230,-0.210$ & $0.450,-0.387$ \\
\hline \multicolumn{3}{|c|}{$\begin{array}{l}{ }^{a} \mathrm{R} 1=\sum\left\|F_{\mathrm{o}}|-| F_{\mathrm{c}}\right\| / \sum\left|F_{\mathrm{o}}\right|{ }^{b}{ }_{\mathrm{wR} 2} 2=\left[\sum w\left(F_{\mathrm{o}}{ }^{2}-F_{\mathrm{c}}^{2}\right)^{2} / \sum w\left(F_{\mathrm{o}}{ }^{2}\right)^{2}\right]^{1 / 2}, \\
\text { where } w=1 /\left[\sigma^{2}\left(F_{\mathrm{o}}^{2}\right)+(a P)^{2}+b P\right] \text { and } P=\left(F_{\mathrm{o}}^{2}+F_{\mathrm{c}}^{2}\right) / 3 .\end{array}$} \\
\hline
\end{tabular}

out under a dry nitrogen atmosphere using a Braun Labmaster drybox or standard Schlenk line techniques. Glassware and vials used in the polymerization were dried in an oven at $120^{\circ} \mathrm{C}$ overnight and exposed three times to vacuum-nitrogen cycles. All solvents and reagents used were dried and purified before use. Toluene (Sigma-Aldrich, 99.5\%) and hexane (Sigma-Aldrich, 99\%) were preliminarily dried over $\mathrm{CaCl}_{2}$, while THF (Sigma-Aldrich, 99\%) was preliminarily treated with potassium hydroxide. Then, all solvents were purified by distillation from sodium under a nitrogen atmosphere. Ligands used for the synthesis of complexes were anhydrificated under vacuum with $\mathrm{P}_{2} \mathrm{O}_{5}$. Lactide was purified by crystallization from dry toluene and then stored over $\mathrm{P}_{2} \mathrm{O}_{5}$. Isopropyl alcohol and tert-butyl alcohol were dried and distilled over magnesium turnings and stored over $4 \AA$ molecular sieves. Deuterated solvents were dried using molecular sieves. All other chemicals were commercially available and used as received unless otherwise stated.

Instruments and Measurements. The NMR spectra were recorded on Bruker Avance 400 spectrometer $\left({ }^{1} \mathrm{H}, 400.01 \mathrm{MHz}\right.$; ${ }^{13} \mathrm{C}, 100.62 \mathrm{MHz}$ ) at $25{ }^{\circ} \mathrm{C}$, unless otherwise stated. Deuterated solvents were purchased from Cambridge Isotope Laboratories, Inc., degassed, and dried over activated $4 \AA$ molecular sieves prior to use. Chemical shifts $(\delta)$ are listed as parts per million, and coupling 
constants $(J)$ are given in hertz. ${ }^{1} \mathrm{H}$ NMR spectra are referenced using the residual solvent peak at $\delta 7.16$ for $\mathrm{C}_{6} \mathrm{D}_{6}, \delta 7.27$ for $\mathrm{CDCl}_{3}$, and $\delta$ 5.32 for $\mathrm{CD}_{2} \mathrm{Cl}_{2} .{ }^{13} \mathrm{C}$ NMR spectra are referenced using the residual solvent peak at $\delta 128.39$ for $\mathrm{C}_{6} \mathrm{D}_{6}, \delta 77.23$ for $\mathrm{CDCl}_{3}$, and $\delta 53.84$ for $\mathrm{CD}_{2} \mathrm{Cl}_{2}$. Variable-temperature ${ }^{1} \mathrm{H}$ NMR experiments were recorded with a Bruker ASCEND 600 spectrometer in toluene- $d_{8}$ using a J. Young NMR tube.

The 2D EXSY spectra were recorded at $333 \mathrm{~K}_{\text {in }} \mathrm{C}_{6} \mathrm{D}_{6}$ for 1,2 , and 5 and in $\mathrm{CDCl}_{3}$ for 3 at different mixing times $(300-700 \mathrm{~ms})$. The rate constants $(k)$ were calculated employing the equations reported below, ${ }^{20}$ in which $k^{\prime}$ is the sum of the forward and reverse reaction rates, $\tau_{\omega}$ is the mixing time, $I_{\mathrm{AB}}$ and $I_{\mathrm{BA}}$ are the cross-peak intensities, and $I_{\mathrm{AA}}$ and $I_{\mathrm{BB}}$ are the diagonal peak intensities:

$$
\begin{aligned}
& k^{\prime}=1 / \tau_{\omega} \ln [(r+1) /(r-1)] \\
& r=4\left(I_{\mathrm{AA}}+I_{\mathrm{BB}}\right) /\left(I_{\mathrm{AB}}+I_{\mathrm{BA}}\right)
\end{aligned}
$$

Because the forward and reverse rate constants are equal in these cases, the rate for the $\Lambda-\Delta$ interconversion is given by $k=k^{\prime} / 2$. The free energy of activation $\left(\Delta G^{\ddagger}\right)$ was calculated using the equation $\Delta G^{\ddagger}$ $=-R T \ln k h / T K_{\mathrm{B}}$.

A variable-temperature NMR study for 4 was performed with a Bruker ASCEND 600 instrument in $\mathrm{CD}_{2} \mathrm{Cl}_{2}$ using $5 \mathrm{~mm}$ NMR tubes equipped with J. Young valves. The chemical shifts are referenced to tetramethylsilane as an external standard. The analysis was referenced to the methylene protons of the $\mathrm{OSSO}_{\text {Cum }}$ ligand that consist of a simple two-spin (not coupled) system and produce two singlets in the slow-exchange regime at $-50{ }^{\circ} \mathrm{C}$ (Figure $\mathrm{S} 13$ in the Supporting Information). NMR simulations were performed using the DNMR module of Topspin 3.0 (Bruker). Final simulated line shapes were obtained via an iterative parameter search upon the exchange constant $k$. The activation parameters $\Delta H^{\ddagger}$ and $\Delta S^{\ddagger}$ were determined from the inverse temperature plot of $\ln (k / T)$. Estimated standard deviations $(\sigma)$ in the slope and $y$ intercept of the Eyring plot determined the error in $\Delta H^{\ddagger}$ and $\Delta S^{\ddagger}$, respectively. The standard deviation in $\Delta G^{\ddagger}$ was determined from the formula $\sigma\left(\Delta G^{\ddagger}\right)^{2}=\sigma\left(\Delta H^{\ddagger}\right)^{2}+\left[T \sigma\left(\Delta S^{\ddagger}\right)\right]^{2}-$ $2 T \sigma\left(\Delta H^{\ddagger}\right) \sigma\left(\Delta S^{\ddagger}\right)$.

In the case of polylactide samples obtained from the polymerization of rac-LA, the evaluation of the probability to obtain an $r$ diad $\left(P_{r}\right)$ was made by an analysis of the relative intensities of the tetrad signals of the ${ }^{1} \mathrm{H}$ NMR homonuclear decoupled spectrum $\left(\mathrm{CDCl}_{3}, 300 \mathrm{MHz}\right.$, ppm): $\mathrm{mrm}$ (5.16), $\mathrm{mmm}$ (5.17), $\mathrm{mmr} / \mathrm{rmm}$ (5.18 and 5.22), and $\mathrm{rmr}$ (5.23). ${ }^{17}$ Electrospray ionization mass spectra were acquired using a Micromass Quattro micro API triple quadrupole mass spectrometer equipped with an electrospray ion source (Waters, Milford, MA). Acetonitrile was added to the samples, and the solutions were continuously infused into the electrospray ionization (ESI) ion source at a rate of $10 \mu \mathrm{L} / \mathrm{min}$ using the instrument syringe pump. The LCQ ion source was operated at $4 \mathrm{kV}$, and the capillary heater was set to $100{ }^{\circ} \mathrm{C}$. Nitrogen was used as the nebulizing gas, and nitrogen was used as the damping gas and collision gas in the mass analyzer. The positive ion mode was used for all analyses. No cationizing agents were used for ESI measurements because $\mathrm{K}^{+}, \mathrm{Na}^{+}$, and $\mathrm{H}^{+}$adduct ions were detectable at high intensity. The origin of these alkali metals was apparently ambient contaminants. The molecular weights $\left(M_{\mathrm{n}}\right.$ and $\left.M_{\mathrm{w}}\right)$ and the molecular mass distributions $\left(M_{\mathrm{n}} / M_{\mathrm{w}}\right)$ of polymer samples were measured by gel permeation chromatography (GPC) at $30{ }^{\circ} \mathrm{C}$, using THF as solvent, a $1 \mathrm{~mL} / \mathrm{min}$ flow rate of the eluent, and narrow polystyrene standards as references. The measurements were performed on a Waters 1525 binary system equipped with a Waters 2414 RI detector using four Styragel columns (range 1000-1000000 $\AA$ ). Every value was the average of two independent measurements. The values were corrected using the factor of 0.58 for polylactide according to the literature. ${ }^{21}$

Synthesis of the Proligands. The OSSO ligands used in this work were prepared by nucleophilic substitution of the suitable 2(bromomethyl)phenol with benzene-1,2-dithiol using a modified literature procedure. ${ }^{12,22}$

Synthesis of 2-(Bromomethyl)-4,6-bis(2-phenylpropan-2-yl)phenol. In a round-bottomed flask, equipped with a magnetic stirrer, 2,4-bis(2-phenylpropan-2-yl)phenol (10.0 g, $30.3 \mathrm{mmol})$ was dissolved in acetic glacial acid (ca. $100 \mathrm{~mL})$ and paraformaldehyde $(1.0 \mathrm{~g}, 33.3$ mmol, 1.1 equiv) was added. The reaction mixture was stirred for $2 \mathrm{~h}$ at room temperature. Then, a solution of $33 \% \mathrm{HBr}$ in acetic acid (34 $\mathrm{mL}, 194.3 \mathrm{mmol}$, 6.4 equiv) was added dropwise, and the resulting yellow solution was stirred for $90 \mathrm{~min}$. After it was stirred, the reaction mixture was poured into a cold bath $\left(T=0{ }^{\circ} \mathrm{C}\right)$ and extracted with $\mathrm{CH}_{2} \mathrm{Cl}_{2}(3 \times 50 \mathrm{~mL})$. The organic solvent was removed under vacuum and an orange viscous oil was obtained. Finally, the crude oil was dissolved in petroleum ether $(10 \mathrm{~mL})$ and stored at $-20^{\circ} \mathrm{C}$ overnight. The desired product was collected as a white solid ( $77 \%$ yield). Spectroscopic data are as follows. ${ }^{1} \mathrm{H}$ NMR (300 MHz, $\mathrm{CDCl}_{3}, 25$ $\left.{ }^{\circ} \mathrm{C}\right): \delta 7.37-7.25(\mathrm{~m}, 10 \mathrm{H}, \mathrm{Ar}), 7.22-7.18(\mathrm{~m}, 1 \mathrm{H}, \mathrm{Ar}), 7.14\left(\mathrm{~d}, J_{\mathrm{HH}}=\right.$ $2.2 \mathrm{~Hz}, 1 \mathrm{H}, \mathrm{Ar}), 4.60(\mathrm{br}, 1 \mathrm{H}, \mathrm{OH}), 4.45\left(\mathrm{~s}, 2 \mathrm{H}, \mathrm{CH}_{2}\right), 1.75(\mathrm{~s}, 6 \mathrm{H}$, $\left.\mathrm{C}\left(\mathrm{CH}_{3}\right)_{2} \mathrm{Ph}\right), 1.63\left(\mathrm{~s}, 6 \mathrm{H}, \mathrm{C}\left(\mathrm{CH}_{3}\right)_{2} \mathrm{Ph}\right) .{ }^{13} \mathrm{C} \mathrm{NMR}(75.4 \mathrm{MHz}$, $\left.\mathrm{CDCl}_{3}, 25^{\circ} \mathrm{C}\right): \delta 150.8,150.3,147.9,142.7,135.4,129.5,128.2,127.8$, 127.5, 126.9, 126.2, 126.1, 125.9, 125.4, 42.8, 42.1, 31.2, 30.5, 29.8.

Synthesis of $6,6^{\prime}-((1,2-$ Phenylenebis(sulfanediyl))bis(methylene))bis(2,4-bis(2-phenylpropan-2-yl)phenol) $\left(\mathrm{OSSO}_{\mathrm{Cum}}-\mathrm{H}\right)$. In a roundbottomed flask, equipped with a magnetic stirrer, 1,2-benzenedithiol $(0.50 \mathrm{~g}, 3.51 \mathrm{mmol})$ was dissolved in dry THF $(10 \mathrm{~mL})$. Then, a solution of sodium tert-butoxide ( $0.68 \mathrm{~g}, 7.08 \mathrm{mmol}, 2$ equiv) in $20 \mathrm{~mL}$ of dry THF was added dropwise to the dithiol solution. The subsequent formation of sodium salt was evident when the reaction mixture appeared as a white suspension. Finally, a THF solution (20 $\mathrm{mL}$ ) of 2-(bromomethyl)-4,6-bis(2-phenylpropan-2-yl)phenol was added to the mixture and the reaction was carried out overnight at room temperature. The solvent was distilled off, water was added until dissolution of $\mathrm{NaBr}$ byproduct, and the aqueous phase was extracted twice with methylene chloride. The combined organic phases were dried with $\mathrm{Na}_{2} \mathrm{SO}_{4}$, and after evaporation of the solvent, the resulting crude oil was purificated by crystallization in petroleum ether at room temperature. The ligand is an off-white solid. $78 \%$ yield. Single crystals were grown from toluene/THF $(1 / 1 \mathrm{v} / \mathrm{v})$. Spectroscopic data are as follows. ${ }^{1} \mathrm{H}$ NMR $\left(300 \mathrm{MHz}, \mathrm{CDCl}_{3}, 25{ }^{\circ} \mathrm{C}\right): \delta 7.32-7.25(\mathrm{~m}, 12 \mathrm{H}$, $\mathrm{Ar}), 7.19(\mathrm{~m}, 10 \mathrm{H}, \mathrm{Ar}), 7.01(\mathrm{~m}, 4 \mathrm{H}, \mathrm{Ar}), 6.86(\mathrm{~m}, 2 \mathrm{H}, \mathrm{Ar}), 4.88(\mathrm{br} \mathrm{s}$, $2 \mathrm{H}, \mathrm{OH}), 3.96\left(\mathrm{~s}, 4 \mathrm{H}, \mathrm{CH}_{2}\right), 1.61\left(\mathrm{~s}, 24 \mathrm{H}, \mathrm{CH}_{3}\right) .{ }^{1} \mathrm{H}$ NMR $(250$ $\left.\mathrm{MHz}, \mathrm{C}_{6} \mathrm{D}_{6}, 25^{\circ} \mathrm{C}\right): \delta 7.51-7.31(\mathrm{~m}, 26 \mathrm{H}, \mathrm{Ar}), 7.01\left(\mathrm{~d}, J_{\mathrm{HH}}=2.2 \mathrm{~Hz}\right.$, $2 \mathrm{H}, \mathrm{Ar}), 5.03(\mathrm{~s}, 2 \mathrm{H}, \mathrm{OH}), 4.11\left(\mathrm{~s}, 4 \mathrm{H}, \mathrm{CH}_{2}\right), 1.76\left(\mathrm{~s}, 24 \mathrm{H}, \mathrm{CH}_{3}\right)$. ${ }^{13} \mathrm{C}$ NMR $\left(62.9 \mathrm{MHz}, \mathrm{C}_{6} \mathrm{D}_{6}, 25{ }^{\circ} \mathrm{C}\right): \delta 202.40,201.39,200.27,193.23$, 188.32 , 186.59, 182.38, 180.23, 179.25, 178.92, 178.05, 177.27, 176.81, 176.00, 174.85, 93.82, 93.29, 85.11, 82.30, 80.99. Anal. Calcd for $\mathrm{C}_{56} \mathrm{H}_{58} \mathrm{O}_{2} \mathrm{~S}_{2}$ : C, 81.31; H, 7.07; S, 7.75. Found: C, 81.58; H, 7.29; S, 7.51. $[\mathrm{M}+\mathrm{Na}]^{+}=848.9 \mathrm{~m} / \mathrm{z}$

Synthesis of 6,6'-((1,2-Phenylenebis(sulfanediyl))bis(methylene))bis(2,4-di-tert-butylphenol) (OSSO$\left.{ }_{t B u}-H\right)$. The synthesis of $\mathrm{OSSO}_{\mathrm{tBu}}{ }^{-}$ $\mathrm{H}$ was performed according to the same procedure as for $\mathrm{OSSO}_{\mathrm{Cum}}-\mathrm{H}$. Yield: $75 \%$. Spectroscopic data are as follows. ${ }^{1} \mathrm{H}$ NMR $(250 \mathrm{MHz}$, $\left.\mathrm{CDCl}_{3}, 25^{\circ} \mathrm{C}\right): \delta 7.37-7.33(\mathrm{~m}, 2 \mathrm{H}, \mathrm{Ar}), 7.22\left(\mathrm{~d}, J_{\mathrm{HH}}=2.4 \mathrm{~Hz}, 2 \mathrm{H}\right.$, Ar), 7.16-7.10 (m, 2H, Ar), $6.87\left(\mathrm{~d}, J_{\mathrm{HH}}=2.4 \mathrm{~Hz} 2 \mathrm{H}, \mathrm{Ar}\right), 6.10$ (s, $2 \mathrm{H}, \mathrm{OH}), 4.14\left(\mathrm{~s}, 4 \mathrm{H}, \mathrm{CH}_{2}\right), 1.42\left(\mathrm{~s}, 18 \mathrm{H}, \mathrm{CH}_{3}\right), 1.22\left(\mathrm{~s}, 18 \mathrm{H}, \mathrm{CH}_{3}\right)$. ${ }^{1} \mathrm{H}$ NMR $\left(250 \mathrm{MHz}, \mathrm{C}_{6} \mathrm{D}_{6}, 25{ }^{\circ} \mathrm{C}\right): \delta 7.39(\mathrm{~m}, 2 \mathrm{H}, \mathrm{Ar}), 7.08\left(\mathrm{t}, J_{\mathrm{HH}}=\right.$ $8.6 \mathrm{~Hz}, 2 \mathrm{H}, \mathrm{Ar}), 6.84(\mathrm{~s}, 2 \mathrm{H}, \mathrm{OH}), 6.65\left(\mathrm{t}, J_{\mathrm{HH}}=8.6 \mathrm{~Hz}, 2 \mathrm{H}, \mathrm{Ar}\right), 6.27$ $(\mathrm{s}, 2 \mathrm{H}, \mathrm{Ar}), 3.82\left(\mathrm{~s}, 4 \mathrm{H}, \mathrm{CH}_{2}\right), 1.57\left(\mathrm{~s}, 18 \mathrm{H}, \mathrm{CH}_{3}\right), 1.23(\mathrm{~s}, 18 \mathrm{H}$, $\left.\mathrm{CH}_{3}\right) .{ }^{13} \mathrm{C}$ NMR $\left(75.4 \mathrm{MHz}, \mathrm{CDCl}_{3}, 25^{\circ} \mathrm{C}\right): \delta 151.63,142.64,137.24$, $137.06,132.92,128.29,125.58,124.08,121.82,37.34,35.16,34.39$, 31.71, 30.05. MS $(m / z):[\mathrm{M}+\mathrm{Na}]^{+}$601.7.

Synthesis of 6,6'-((1,2-Phenylenebis(sulfanediyl))bis(methylene))bis(2,4-dichlorophenol)) $\left(\mathrm{OSSO}_{\mathrm{Cl}}-\mathrm{H}\right)$. The synthesis of $\mathrm{OSSO}_{\mathrm{Cl}}-\mathrm{H}$ was performed according to the same procedure as for $\mathrm{OSSO}_{\mathrm{Cum}}-\mathrm{H}$. Yield: $50 \%$. Spectroscopic data are as follows. ${ }^{1} \mathrm{H}$ NMR $\left(300 \mathrm{MHz}, \mathrm{CDCl}_{3}\right.$, $\left.25^{\circ} \mathrm{C}\right): \delta 7.27-7.24(\mathrm{~m}, 4 \mathrm{H}, \mathrm{Ar}), 7.19-715(\mathrm{~m}, 2 \mathrm{H}, \mathrm{Ar}), 7.02\left(\mathrm{~d}, J_{\mathrm{HH}}\right.$ $=2.6 \mathrm{~Hz}, 2 \mathrm{H}, \mathrm{Ar}), 5.87$ (br s, $2 \mathrm{H}, \mathrm{OH}), 4.11\left(\mathrm{~s}, 4 \mathrm{H}, \mathrm{CH}_{2}\right) .{ }^{1} \mathrm{H}$ NMR $\left(250 \mathrm{MHz}, \mathrm{C}_{6} \mathrm{D}_{6}, 25{ }^{\circ} \mathrm{C}\right): \delta 7.05-7.01(\mathrm{~m}, 2 \mathrm{H}, \mathrm{Ar}), 6.88-6.84(\mathrm{dd}$, $\left.J_{\mathrm{HH}}=10.9 \mathrm{~Hz}, 4 \mathrm{H}, \mathrm{Ar}\right), 6.77-6.73(\mathrm{~m}, 2 \mathrm{H}, \mathrm{Ar}), 5.50(\mathrm{~s}, 2 \mathrm{H}, \mathrm{OH})$, $3.78\left(\mathrm{~s}, 4 \mathrm{H}, \mathrm{CH}_{2}\right) .{ }^{13} \mathrm{C}$ NMR $\left(62.9 \mathrm{MHz}, \mathrm{C}_{6} \mathrm{D}_{6}, 25{ }^{\circ} \mathrm{C}\right): \delta 149.19$, $137.87,131.69,129.72,128.18,127.90,126.96,125.68,121.34,33.45$. Anal. Calcd for $\mathrm{C}_{20} \mathrm{H}_{14} \mathrm{Cl}_{4} \mathrm{O}_{2} \mathrm{~S}_{2}$ : C, 48.80; H, 2.87; S, 13.03. Found: $\mathrm{C}$, 48.94; H, 2.96; S, 12.94. MS $(\mathrm{m} / z):[\mathrm{M}+\mathrm{Na}]^{+}$515.2. 
Synthesis of $\left(\mathrm{OSSO}_{\mathrm{tBu}}\right) \mathrm{Zr}\left(\mathrm{O}^{t} \mathrm{Bu}\right)_{2}$ (1). A solution of $\mathrm{Zr}\left(\mathrm{O}^{t} \mathrm{Bu}\right)_{4}$ $(0.33 \mathrm{~g}, 0.86 \mathrm{mmol}$, $)$ in toluene $(5 \mathrm{~mL})$ was added to a stirred solution of $\mathrm{OSSO}_{\mathrm{tBu}}-\mathrm{H}(0.50 \mathrm{~g}, 0.86 \mathrm{mmol})$ in toluene $(5 \mathrm{~mL})$ at room temperature. The resulting pale yellow solution was stirred for $2 \mathrm{~h}$, after which the volatiles were removed under vacuum. The crude product was washed with hexane to give 1 as a yellow solid ( $0.46 \mathrm{~g}$, $66 \%)$ that was pure according to ${ }^{1} \mathrm{H}$ NMR and elemental analysis. Spectroscopic data are as follows. ${ }^{1} \mathrm{H}$ NMR $\left(600 \mathrm{MHz}\right.$, Tol- $\left.-d_{8}, 25^{\circ} \mathrm{C}\right)$ : $\delta 7.29\left(\mathrm{~d}, J_{\mathrm{HH}}=2.6 \mathrm{~Hz}, 2 \mathrm{H}, \mathrm{Ar}\right), 6.90-6.88(\mathrm{~m}, 2 \mathrm{H}, \mathrm{Ar}), 6.66-6.63$ $(\mathrm{m}, 2 \mathrm{H}, \mathrm{Ar}), 6.06\left(\mathrm{~d}, J_{\mathrm{HH}}=2.6 \mathrm{~Hz}, 2 \mathrm{H}, \mathrm{Ar}\right), 4.19\left(\mathrm{~d}, J_{\mathrm{HH}}=12.7 \mathrm{~Hz}\right.$, $2 \mathrm{H}, \mathrm{CH}-\mathrm{H}), 3.30\left(\mathrm{~d}, J_{\mathrm{HH}}=12.7 \mathrm{~Hz}, 2 \mathrm{H}, \mathrm{CH}-\mathrm{H}\right), 1.77\left(\mathrm{~s}, 18 \mathrm{H}, \mathrm{CH}_{3}\right)$, $1.57\left(\mathrm{~s}, 18 \mathrm{H}, \mathrm{OC}\left(\mathrm{CH}_{3}\right)_{3}\right), 1.08\left(\mathrm{~s}, 18 \mathrm{H}, \mathrm{CH}_{3}\right) .{ }^{13} \mathrm{C}$ NMR $(75.4 \mathrm{MHz}$, $\left.\mathrm{CD}_{2} \mathrm{Cl}_{2}, 25{ }^{\circ} \mathrm{C}\right): \delta 159.81,139.05,137.57,136.71,136.39,130.55$, 126.04, 123.95, 121.17, 77.47, 41.96, 35.71, 33.17, 33.00, 31.83, 30.86. Anal. Calcd for $\mathrm{C}_{44} \mathrm{H}_{66} \mathrm{O}_{4} \mathrm{~S}_{2} \mathrm{Zr}$ : C, 64.90; H, 8.17; S, 7.88. Found: C, 65.05; H, 8.19; S, 7.84.

Synthesis of $\left(\mathrm{OSSO}_{\mathrm{Cum}}\right) \mathrm{Zr}\left(\mathrm{O}^{t} \mathrm{Bu}\right)_{2}(2)$. $\left(\mathrm{OSSO}_{\mathrm{Cum}}\right) \mathrm{Zr}\left(\mathrm{O}^{t} \mathrm{Bu}\right)_{2}$ was prepared in high yield $(70 \%)$ from $\mathrm{OSSO}_{\mathrm{Cum}}-\mathrm{H}(0.50 \mathrm{~g}, 0.61 \mathrm{mmol})$ and $\mathrm{Zr}\left(\mathrm{O}^{t} \mathrm{Bu}\right)_{4}(0.23 \mathrm{~g}, 0.61 \mathrm{mmol})$ as described above for $\left(\mathrm{OSSo}_{\mathrm{tBu}}\right) \mathrm{Zr}\left(\mathrm{O}^{t} \mathrm{Bu}\right)_{2}$ (1). Spectroscopic data are as follows. ${ }^{1} \mathrm{H}$ NMR (600 MHz, Tol- $\left.d_{8}, 25^{\circ} \mathrm{C}\right): \delta 7.38-7.36(\mathrm{~m}, 4 \mathrm{H}, \mathrm{Ar}), 7.19-$ $7.04(\mathrm{~m}, 18 \mathrm{H}, \mathrm{Ar}), 6.94-6.88(\mathrm{~m}, 2 \mathrm{H}, \mathrm{Ar}), 6.72-6.70(\mathrm{~m}, 2 \mathrm{H}, \mathrm{Ar})$, $5.95\left(\mathrm{~d}, J_{\mathrm{HH}}=2.6 \mathrm{~Hz}, 2 \mathrm{H}, \mathrm{Ar}\right), 4.00\left(\mathrm{~d}, J_{\mathrm{HH}}=12.7 \mathrm{~Hz}, 2 \mathrm{H}, \mathrm{CH}-\mathrm{H}\right)$, $3.13\left(\mathrm{~d}, J_{\mathrm{HH}}=12.7 \mathrm{~Hz}, 2 \mathrm{H}, \mathrm{CH}-\mathrm{H}\right), 2.19\left(\mathrm{~s}, 6 \mathrm{H}, \mathrm{CH}_{3}\right), 1.71(\mathrm{~s}, 6 \mathrm{H}$, $\left.\mathrm{CH}_{3}\right), 1.39$ (s, $\left.12 \mathrm{H}, \mathrm{CH}_{3}\right), 1.33\left(\mathrm{~s}, 18 \mathrm{H}, \mathrm{OC}\left(\mathrm{CH}_{3}\right)_{3}\right) .{ }^{13} \mathrm{C} \mathrm{NMR}(75.4$ $\left.\mathrm{MHz}, \mathrm{CD}_{2} \mathrm{Cl}_{2}, 25{ }^{\circ} \mathrm{C}\right): \delta 151.60,150.59,149.57,142.46,137.43$, 135.74, 131.53, 129.33, 128.40, 128.17, 127.31, 127.22, 127.02, 126.47, 125.94, 125.13, 124.13, 69.34, 42.97, 42.46, 34.22, 31.55, 31.24, 29.95. Anal. Calcd for $\mathrm{C}_{64} \mathrm{H}_{74} \mathrm{O}_{4} \mathrm{~S}_{2} \mathrm{Zr} \cdot \mathrm{C}_{7} \mathrm{H}_{8}: \mathrm{C}, 73.85 ; \mathrm{H}, 7.16 ; \mathrm{S}, 5.55$. Found: C, 73.70; $\mathrm{H}, 7.14 ; \mathrm{S}, 5.56$.

Synthesis of $\left(\mathrm{OSSO}_{\mathrm{Cl}}\right)_{2} \mathrm{Zr}$ (3). A solution of $\mathrm{Zr}\left(\mathrm{O}^{t} \mathrm{Bu}\right)_{4}(0.19 \mathrm{~g}$, $0.50 \mathrm{mmol})$ in toluene $(5 \mathrm{~mL})$ was added to a stirred solution of OSSO $_{\mathrm{Cl}^{-}} \mathrm{H}(0.50 \mathrm{~g}, 1.01 \mathrm{mmol})$ in toluene $(5 \mathrm{~mL})$ at room temperature. The resulting pale yellow solution was stirred for $2 \mathrm{~h}$, after which the volatiles were removed under vacuum. The crude product was washed with hexane to give 1 as a yellow solid $(0.62 \mathrm{~g}$, $57 \%)$ that was pure according to ${ }^{1} \mathrm{H}$ NMR and elemental analysis. Spectroscopic data are as follows. ${ }^{1} \mathrm{H}$ NMR $\left(600 \mathrm{MHz}, \mathrm{Tol}-d_{8}, 25^{\circ} \mathrm{C}\right)$ : $\delta 7.04\left(\mathrm{~d}, J_{\mathrm{HH}}=2.6 \mathrm{~Hz}, 4 \mathrm{H}, \mathrm{Ar}\right), 6.75-6.73(\mathrm{~m}, 4 \mathrm{H}, \mathrm{Ar}), 6.60-6.58$ $(\mathrm{m}, 4 \mathrm{H}, \mathrm{Ar}), 5.88\left(\mathrm{~d}, J_{\mathrm{HH}}=2.6 \mathrm{~Hz}, 4 \mathrm{H}\right), 5.59\left(\mathrm{~d}, J_{\mathrm{HH}}=12.8 \mathrm{~Hz}, 4 \mathrm{H}\right.$, $\mathrm{CH}-\mathrm{H}), 3.19$ (d, $\left.\mathrm{J}_{\mathrm{HH}}=12.8 \mathrm{~Hz}, 4 \mathrm{H}, \mathrm{CH}-\mathrm{H}\right) .{ }^{13} \mathrm{C}$ NMR $(75.4 \mathrm{MHz}$, $\left.\mathrm{CD}_{2} \mathrm{Cl}_{2}, 25{ }^{\circ} \mathrm{C}\right): \delta 157.40,136.66,135.52,131.08,129.10,127.83$, 126.95, 124.61, 122.70, 41.40. Anal. Calcd for $\mathrm{C}_{40} \mathrm{H}_{24} \mathrm{Cl}_{8} \mathrm{O}_{4} \mathrm{~S}_{4} \mathrm{Zr}$ : C, 44.83; H, 2.26; S, 11.97. Found: C, 44.92; H, 2.28; S, 11.93 .

Synthesis of $\left(\mathrm{OSSO}_{\mathrm{Cum}}\right) \mathrm{Ti}\left(\mathrm{O}^{i} \mathrm{Pr}\right)_{2}$ (4). A solution of $\mathrm{Ti}\left(\mathrm{O}^{i} \mathrm{Pr}\right)_{4}$ $(0.17 \mathrm{~g}, 0.47 \mathrm{mmol})$ in toluene $(5 \mathrm{~mL})$ was added to a stirred solution of $\mathrm{OSSO}_{\mathrm{Cum}}-\mathrm{H}(0.50 \mathrm{~g}, 0.47 \mathrm{mmol})$ in toluene $(5 \mathrm{~mL})$ at room temperature. The resulting pale yellow solution was stirred for $2 \mathrm{~h}$, after which the volatiles were removed under vacuum. The crude product was washed with hexane to give 1 as a yellow solid $(0.30 \mathrm{~g}$, $64 \%)$ that was pure according to ${ }^{1} \mathrm{H}$ NMR and elemental analysis. Spectroscopic data are as follows. ${ }^{1} \mathrm{H}$ NMR $\left(600 \mathrm{MHz}, \mathrm{CD}_{2} \mathrm{Cl}_{2}, 25\right.$ $\left.{ }^{\circ} \mathrm{C}\right): \delta$ 7.34-7.33 (m, 2H, Ar), 7.24-7.04 (m, 20H, Ar), 6.89-6.87 (m, $4 \mathrm{H}, \mathrm{Ar}), 6.03$ (d, $\left.J_{\mathrm{HH}}=2.5 \mathrm{~Hz}, 2 \mathrm{H}, \mathrm{Ar}\right), 4.38(\mathrm{~m}, 2 \mathrm{H}, \mathrm{OCH}), 3.61$ (br s, $\left.4 \mathrm{H}, \mathrm{CH}_{2}\right), 1.78\left(\right.$ br s, $\left.12 \mathrm{H}, \mathrm{CH}_{3}\right), 1.38\left(\mathrm{~s}, 12 \mathrm{H}, \mathrm{CH}_{3}\right), 1.05(\mathrm{~d}$, $\left.J_{\mathrm{HH}}=5.4 \mathrm{~Hz}, 12 \mathrm{H}, \mathrm{CH}\left(\mathrm{CH}_{3}\right)_{2}\right){ }^{13} \mathrm{C} \operatorname{NMR}\left(62.9 \mathrm{MHz}, \mathrm{CD}_{2} \mathrm{Cl}_{2}, 25\right.$ $\left.{ }^{\circ} \mathrm{C}\right): \delta 161.42,152.44,151.98,138.91,137.65,137.58,135.46,130.52$, $128.18,127.69,127.64,127.02,126.80,125.88,125.56,125.03,122.00$, 79.40, 42.60, 41.18, 31.13, 25.99. Anal. Calcd for $\mathrm{C}_{62} \mathrm{H}_{70} \mathrm{O}_{4} \mathrm{~S}_{2} \mathrm{Ti}: \mathrm{C}$, 75.13; H, 7.12; S, 6.47. Found: C, 75.29; H, 7.14; S, 6.44.

Synthesis of $\left(\mathrm{OSSO}_{\mathrm{Cum}}\right) \mathrm{Hf}\left(\mathrm{O}^{t} \mathrm{Bu}\right)_{2}$ (5). A solution of $\mathrm{Hf}\left(\mathrm{O}^{t} \mathrm{Bu}\right)_{4}$ $(0.28 \mathrm{~g}, 0.61 \mathrm{mmol})$ in toluene $(5 \mathrm{~mL})$ was added to a stirred solution of $\mathrm{OSSO}_{\mathrm{Cum}}-\mathrm{H}(0.50 \mathrm{~g}, 0.61 \mathrm{mmol})$ in toluene $(5 \mathrm{~mL})$ at room temperature. The resulting pale yellow solution was stirred for $2 \mathrm{~h}$, after which the volatiles were removed under vacuum. The crude product was washed with hexane to give $\mathbf{1}$ as a yellow solid $(0.37 \mathrm{~g}$, $53 \%)$ that was pure according to ${ }^{1} \mathrm{H}$ NMR and elemental analysis. Single crystals of the complex were grown from toluene at $-20^{\circ} \mathrm{C}$. Spectroscopic data are as follows. ${ }^{1} \mathrm{H}$ NMR $\left(600 \mathrm{MHz}, \mathrm{Tol}-d_{8}, 25^{\circ} \mathrm{C}\right)$ : $\delta 7.38-7.36(\mathrm{~m}, 2 \mathrm{H}, \mathrm{Ar}), 7.15-7.13\left(\mathrm{q}, J_{\mathrm{HH}}=6.1 \mathrm{~Hz}, 2 \mathrm{H}, \mathrm{Ar}\right), 7.07-$ $6.92(\mathrm{~m}, 20 \mathrm{H}, \mathrm{Ar}), 6.75-6.73(\mathrm{~m}, 2 \mathrm{H}, \mathrm{Ar}), 5.95\left(\mathrm{~d}, J_{\mathrm{HH}}=2.4 \mathrm{~Hz}, 2 \mathrm{H}\right.$, $\mathrm{Ar}), 4.05\left(\mathrm{~d}, 2 \mathrm{H}, J_{\mathrm{HH}}=12.6 \mathrm{~Hz}, \mathrm{CH}-\mathrm{H}\right), 3.20\left(\mathrm{~d}, J_{\mathrm{HH}}=12.6 \mathrm{~Hz}, 2 \mathrm{H}\right.$, $\mathrm{CH}-\mathrm{H}), 2.14\left(\mathrm{~s}, 6 \mathrm{H}, \mathrm{CH}_{3}\right), 1.74\left(\mathrm{~s}, 6 \mathrm{H}, \mathrm{CH}_{3}\right), 1.36\left(\mathrm{~s}, 12 \mathrm{H}, \mathrm{CH}_{3}\right)$, $1.33\left(\mathrm{~s}, 18 \mathrm{H}, \mathrm{OC}\left(\mathrm{CH}_{3}\right)_{3}\right) \cdot{ }^{13} \mathrm{C}$ NMR $\left(75.4 \mathrm{MHz}, \mathrm{CD}_{2} \mathrm{Cl}_{2}, 25{ }^{\circ} \mathrm{C}\right): \delta$ $159.47,152.37,152.04,138.22,138.02,136.78,136.46,130.76,128.17$, $127.83,127.03,126.84,125.54,125.18,121.30,76.85,42.91,42.41$, 41.66, 33.10, 32.79, 31.42, 30.85, 28.29. Anal. Calcd for $\mathrm{C}_{64} \mathrm{H}_{74} \mathrm{HfO}_{4} \mathrm{~S}_{2}$ : C, 66.85; H, 6.49; S, 5.58. Found: C, 66.97; H, 6.51; S, 5.54 .

Lactide Polymerizations. In a typical polymerization, in a glovebox, a Schlenk flask $\left(10 \mathrm{~cm}^{3}\right)$ was charged sequentially with rac-lactide $(0.180 \mathrm{~g}, 1.25 \mathrm{mmol})$ and the precatalyst $(12.5 \mu \mathrm{mol})$ dissolved in $2.4 \mathrm{~mL}$ of dry toluene. The mixture was thermostated at the required temperature. At specified time intervals, a small amount of the polymerization mixture was sampled by a pipet and quenched in wet $\mathrm{CDCl}_{3}$ to evaluate the yields. This fraction was subjected to a monomer conversion determination, which was monitored by integration of monomer versus polymer methine resonances in the ${ }^{1} \mathrm{H}$ NMR spectrum $\left(\mathrm{CDCl}_{3}\right)$. After the required polymerization time, the reaction mixture was quenched with wet $n$-hexane. The precipitates collected from the bulk mixture were dried in air, dissolved in dichloromethane, and sequentially precipitated into methanol. The obtained polymer was collected by filtration and further dried in a vacuum oven at $40{ }^{\circ} \mathrm{C}$ for $16 \mathrm{~h}$. The polymer was characterized by NMR spectroscopy and GPC analysis. The chemical shifts of polylactide are $\delta 1.64\left(\mathrm{~d}, 6 \mathrm{H},-\mathrm{CHCH}_{3}-\right)$ and $5.18(\mathrm{q}, 2 \mathrm{H}$, $\left.-\mathrm{CHCH}_{3}-\right)$. The chemical shifts of lactide are $\delta 1.59(\mathrm{~d}, 6 \mathrm{H}$, $\left.-\mathrm{CHCH}_{3}-\right)$ and $4.85\left(\mathrm{t}, 2 \mathrm{H},-\mathrm{CHCH}_{3}-\right)$.

Lactide Polymerizations in the Presence of Alcohol. In a typical polymerization, in a glovebox, a Schlenk flask $\left(10 \mathrm{~cm}^{3}\right)$ was charged sequentially with rac-lactide $(0.180 \mathrm{~g}, 1.25 \mathrm{mmol})$ and the precatalyst $(12.5 \mu \mathrm{mol})$ dissolved in a proper amount of dry toluene to reach a total volume of $2.4 \mathrm{~mL}$. Subsequently, $0.30,0.75$, or $1.5 \mathrm{~mL}$ of a $0.083 \mathrm{M}$ solution of alcohol (isopropyl alcohol or tert-butyl alcohol) in toluene $(25,62.5$, or $125 \mu \mathrm{mol})$ was added. The volume was kept constant to $2.4 \mathrm{~mL}$. The mixture was thermostated at the required temperature. At specified time intervals, a small amount of the polymerization mixture was sampled by a pipet and quenched in wet $\mathrm{CDCl}_{3}$ to evaluate the yields. This fraction was subjected to a monomer conversion determination, which was monitored by integration of monomer versus polymer methine resonances in the ${ }^{1} \mathrm{H}$ NMR spectrum $\left(\mathrm{CDCl}_{3}\right)$. After the required polymerization time, the reaction mixture was quenched with wet $n$-hexane. The precipitates collected from the bulk mixture were dried in air, dissolved in dichloromethane, and sequentially precipitated into methanol. The obtained polymer was collected by filtration and further dried in a vacuum oven at $40{ }^{\circ} \mathrm{C}$ for $16 \mathrm{~h}$. The polymer was characterized by NMR spectroscopy and GPC analysis.

Computational Details. Density functional theory (DFT) calculations were performed with the program suite Gaussian 09. ${ }^{23}$ All geometries were optimization without constraints at the BP86 level: i.e., employing the exchange and correlation functionals of Becke and Perdew, ${ }^{24}$ respectively. The basis set employed was LANL2DZ ${ }^{25}$ with associate effective core potentials for $\mathrm{Zr}$ and $\mathrm{S}$ and $6-31 \mathrm{G}(\mathrm{d})$ for $\mathrm{O}, \mathrm{C}$, and $\mathrm{H}$. Geometry optimizations were performed without symmetry constraints. Stationary point geometries were characterized as local minima on the potential energy surfaces. The absence of imaginary frequencies verified that structures were true minima at their respective levels of theory. The structures of transition states were located by applying Schlegel's synchronous-transit-guided quasiNewton (QST2) method as implemented in GAUSSIAN 09. The transition states were verified with frequency calculations to ensure they were first-order saddle points with only one negative eigenvalue. Cartesian coordinates of all DFT optimized structures are available on request. Structures were visualized by the CYLview program. ${ }^{26}$

Single-Crystal X-ray Crystallography. A suitable crystal of $\left(\mathrm{OSSO}_{\mathrm{Cum}}\right) \mathrm{Zr}\left(\mathrm{O}^{\mathrm{t}} \mathrm{Bu}\right)_{2} \cdot \mathrm{C}_{7} \mathrm{H}_{8}$ was mounted on a goniometer head and cooled to $100 \mathrm{~K}$ in a stream of cold $\mathrm{N}_{2}$ using a Bruker Kryoflex low temperature device, whereas the $\mathrm{OSSO}_{\mathrm{Cum}}-\mathrm{H}$ ligand was mounted on a goniometer head and kept at room temperature. The X-ray intensity 
data for both structures were measured on a Bruker SMART Apex II $\mathrm{CCD}$ area detector diffractometer. Cell dimensions and the orientation matrix were initially determined from a least-squares refinement on reflections measured in three sets of 20 exposures, collected in three different $\omega$ regions, and eventually refined against all data. A full sphere of reciprocal space was scanned by $0.3^{\circ} \omega$ steps. The software SMART $^{27}$ was used for collecting frames of data, indexing reflections, and determining lattice parameters. The collected frames were then processed for integration by the SAINT program, and an empirical absorption correction was applied using SADABS. ${ }^{28}$ The structures were solved by direct methods (SIR 2004) ${ }^{29}$ and subsequent Fourier syntheses and refined by full-matrix least squares on $F^{2}$ (SHELXTL), ${ }^{30}$ using anisotropic thermal parameters for all non-hydrogen atoms. All hydrogen atoms bound to $\mathrm{C}$ atoms were added in calculated positions, included in the final stage of refinement with isotropic thermal parameters, $U(\mathrm{H})=1.2\left[U_{\text {eq }}(\mathrm{C})\right]\left(U(\mathrm{H})=1.5\left[U_{\text {eq }}(\mathrm{C}-\mathrm{Me})\right]\right)$, and allowed to ride on their carrier carbons. The phenolic $\mathrm{H}$ atoms (H100 and $\mathrm{H} 200)$ in the $\mathrm{OSSO}_{\mathrm{Cum}}-H$ ligand were located in the Fourier map and refined with isotropic thermal parameters $\left(U(\mathrm{H})=1.2\left[U_{\text {eq }}(\mathrm{O})\right]\right)$. In the asymmetric unit of $\left(\mathrm{OSSO}_{\mathrm{Cum}}\right) \mathrm{Zr}\left(\mathrm{O}^{\mathrm{t}} \mathrm{Bu}\right)_{2} \cdot \mathrm{C}_{7} \mathrm{H}_{8}$ a toluene solvent molecule is present. Three methyl groups of one tert-butyloxy moiety are disordered over two positions with occupation factors of 78 and $22 \%$, respectively.

Crystal data and details of the data collection for $\left(\mathrm{OSSO}_{\mathrm{Cum}}\right) \mathrm{Zr}$ $\left(\mathrm{O}^{\mathrm{t}} \mathrm{Bu}\right)_{2} \cdot \mathrm{C}_{7} \mathrm{H}_{8}$ and $\mathrm{OSSO}_{\mathrm{Cum}}-\mathrm{H}$ are reported in Table 3. CCDC 1517665 and CCDC 1517664 contain supplementary crystallographic data for this paper. These data can be obtained free of charge from the Cambridge Crystallographic Data Centre via www.ccdc.cam.ac.uk/ data_request/cif.

\section{ASSOCIATED CONTENT}

\section{S Supporting Information}

The Supporting Information is available free of charge on the ACS Publications website at DOI: 10.1021/acs.inorgchem.6b02987.

\section{Crystallographic data (CIF)}

Crystallographic data (CIF)

${ }^{1} \mathrm{H}$ NMR spectra of proligands and complexes, plots of number-averaged molecular vs monomer conversion, pseudo-first-order kinetic plots, and crystallographic data (PDF)

\section{ACKNOWLEDGMENTS}

The authors thank Dr. Patrizia Oliva and Dr. Patrizia Iannece for technical assistance. Financial support is acknowledged from the Ministero dell'Istruzione dell'Università e della Ricerca (MIUR, Roma, Italy, for FARB 2015) and the SPRING cluster (REBIOCHEM research project CTN01_00063_49393). The Centro di Tecnologie Integrate per la Salute (Project PONa3_00138) is acknowledged for the $600 \mathrm{MHz}$ NMR instrument time.

\section{REFERENCES}

(1) (a) Ragauskas, A. J.; Williams, C. K.; Davison, B. H.; Britovsek, G.; Cairney, J.; Eckert, C. A.; Frederick, W. J.; Hallett, J. P.; Leak, D. J.;
Liotta, C. L.; Mielenz, J. R.; Murphy, R.; Templer, R.; Tschaplinski, T. The Path Forward for Biofuels and Biomaterials. Science 2006, 311, 484-489. (b) Mecking, S. Nature or Petrochemistry?-Biologically Degradable Materials. Angew. Chem., Int. Ed. 2004, 43, 1078-1085. (c) Mülhaupt, R. Green Polymer Chemistry and Bio-based Plastics: Dreams and Reality. Macromol. Chem. Phys. 2013, 214, 159-174. (d) Miller, S. A. Sustainable Polymers: Opportunities for the Next Decade. ACS Macro Lett. 2013, 2, 550-554. (e) Tschan, M. J.-L.; Brulé, E.; Haquette, P.; Thomas, C. M. Synthesis of biodegradable polymers from renewable resources. Polym. Chem. 2012, 3, 836-851.

(2) (a) Albertsson, A.-C.; Varma, I. K. Recent developments in ring opening polymerization of lactones for biomedical applications. Biomacromolecules 2003, 4, 1466-1486. (b) Chiellini, E.; Solaro, R. Biodegradable Polymeric Materials. Adv. Mater. 1996, 8, 305-313. (c) Ikada, Y.; Tsuji, H. Biodegradable polyesters for medical and ecological applications. Macromol. Rapid Commun. 2000, 21, 117-132. (d) Auras, R.; Harte, B.; Selke, S. An overview of polylactides as packaging materials. Macromol. Biosci. 2004, 4, 835-864.

(3) Dubois, P.; Coulembier, O.; Raquez, J.-M. Handbook of RingOpening Polymerization; Wiley-VCH: Weinheim, Germany, 2009.

(4) (a) Dijkstra, P. J.; Du, H.; Feijen, J. Single site catalysts for stereoselective ring-opening polymerization of lactides. Polym. Chem. 2011, 2, 520-527. (b) O'Keefe, B. J.; Hillmyer, M. A.; Tolman, W. B. Polymerization of lactide and related cyclic esters by discrete metal complexes. J. Chem. Soc., Dalton Trans. 2001, 2215-2224. (c) Stanford, M. J.; Dove, A. P. Stereocontrolled ring-opening polymerisation of lactide. Chem. Soc. Rev. 2010, 39, 486-494. (d) Dechy-Cabaret, O.; Martin-Vaca, B.; Bourissou, D. Controlled Ring-Opening Polymerization of Lactide and Glycolide. Chem. Rev. 2004, 104, 6147-6176. (e) Thomas, C. M. Stereocontrolled ring-opening polymerization of cyclic esters: synthesis of new polyester microstructures. Chem. Soc. Rev. 2010, 39, 165-173. (f) Buffet, J. C.; Okuda. Initiators for the stereoselective ring-opening polymerization of meso-lactide. Polym. Chem. 2011, 2, 2758-2763.

(5) Sauer, A.; Kapelski, A.; Fliedel, C.; Dagorne, S.; Kol, M.; Okuda, J. Structurally well-defined group 4 metal complexes as initiators for the ring-opening polymerization of lactide monomers. Dalton Trans. 2013, 42, 9007-9023.

(6) (a) Jones, M. D.; Hancock, S. L.; McKeown, P.; Schäfer, P. M.; Buchard, A.; Thomas, L. H.; Mahon, M. F.; Lowe, J. P. Zirconium complexes of bipyrrolidine derived salan ligands for the isoselective polymerisation of rac-lactide. Chem. Commun. 2014, 50, 1596715970. (b) Jones, M. D.; Brady, L.; McKeown, P.; Buchard, A.; Schäfer, P. M.; Thomas, L. H.; Mahon, M. F.; Woodman, T. J.; Lowe, $\mathrm{J}$. Metal influence on the iso- and hetero-selectivity of complexes of bipyrrolidine derived salan ligands for the polymerisation of rac-lactide. Chem. Sci. 2015, 6, 5034-5039.

(7) Sergeeva, E.; Kopilov, J.; Goldberg, I.; Kol, M. Dithiodiolate Ligands: Group 4 Complexes and Application in Lactide Polymerization. Inorg. Chem. 2010, 49, 3977-3979.

(8) (a) Buffet, J.-C.; Okuda, J. Group 4 metal initiators for the controlled stereoselective polymerization of lactide monomers. Chem. Commun. 2011, 47, 4796-4798. (b) Buffet, J.-C.; Martin, A. N.; Kol, M.; Okuda, J. Controlled stereoselective polymerization of lactide monomers by group 4 metal initiators that contain an (OSSO)-type tetradentate bis(phenolate) ligand. Polym. Chem. 2011, 2, 2378-2384.

(9) Stopper, A.; Okuda, J.; Kol, M. Ring-Opening Polymerization of Lactide with $\mathrm{Zr}$ Complexes of $\{\mathrm{ONSO}\}$ Ligands: From Heterotactically Inclined to Isotactically Inclined Poly(lactic acid. Macromolecules 2012, 45, 698-704.

(10) Stopper, A.; Press, K.; Okuda, J.; Goldberg, I.; Kol, M. Zirconium Complexes of Phenylene-Bridged \{ONSO\} Ligands: Coordination Chemistry and Stereoselective Polymerization of racLactide. Inorg. Chem. 2014, 53, 9140-9150.

(11) (a) Della Monica, F.; Luciano, E.; Roviello, G.; Grassi, A.; Milione, S.; Capacchione, C. Group 4 Metal Complexes Bearing Thioetherphenolate Ligands. Coordination Chemistry and RingOpening Polymerization Catalysis. Macromolecules 2014, 47, 28302841. (b) Della Monica, F.; Luciano, E.; Buonerba, A.; Grassi, A.; 
Milione, S.; Capacchione, C. Poly(lactide-co- $\varepsilon$-caprolactone) copolymers prepared using bis-thioetherphenolate group 4 metal complexes: synthesis, characterization and morphology. RSC Adv. 2014, 4, 51262-51267. (c) Luciano, E.; Della Monica, F.; Buonerba, A.; Grassi, A.; Capacchione, C.; Milione, S. Polymerization of ethylene and propylene promoted by group 4 metal complexes bearing thioetherphenolate ligands. Polym. Chem. 2015, 6, 4657-4668. (d) Luciano, E.; Buonerba, A.; Grassi, A.; Milione, S.; Capacchione, C. Thioetherphenolate group 4 metal complexes in the ring opening polymerization of rac- $\beta$-Butyrolactone. J. Polym. Sci., Part A: Polym. Chem. 2016, 54, 3132-3139. (e) Lapenta, R.; Mazzeo, M.; Grisi, F. Monoamidinate titanium complexes: highly active catalysts for the polymerization and copolymerization of L-lactide and $\varepsilon$-caprolactone. RSC Adv. 2015, 5, 87635-87644.

(12) Si, G.; Zhang, L.; Han, B.; Duan, Z.; Li, B.; Dong, J.; Li, X.; Liu, B. Novel chromium complexes with a [OSSO]-type bis(phenolato) dianionic ligand mediate the alternating ring-opening copolymerization of epoxides and phthalic anhydride. Polym. Chem. 2015, 6, 63726377.

(13) Cohen, A.; Yeori, A.; Goldberg, I.; Kol, M. Group 4 Complexes of a New [OSSO]-Type Dianionic Ligand. Coordination Chemistry and Preliminary Polymerization Catalysis Studies. Inorg. Chem. 2007, 46, 8114-8116.

(14) (a) Cohen, A.; Goldberg, I.; Venditto, V.; Kol, M. Oscillating Non-Metallocenes - from Stereoblock-Isotactic Polypropylene to Isotactic Polypropylene via Zirconium and Hafnium Dithiodiphenolate Catalysts. Eur. J. Inorg. Chem. 2011, 2011, 5219-5223. (b) Groysman, S.; Sergeeva, E.; Goldberg, I.; Kol, M. Salophan Complexes of Group IV Metals. Eur. J. Inorg. Chem. 2005, 2005, 2480-2485.

(15) Sauer, A.; Buffet, J.-C.; Spaniol, T. P.; Nagae, H.; Mashima, K.; Okuda, J. Synthesis, Characterization, and Lactide Polymerization Activity of Group 4 Metal Complexes Containing Two Bis(phenolate) Ligands. Inorg. Chem. 2012, 51, 5764-5770.

(16) Zelikoff, A. L.; Kopilov, J.; Goldberg, I.; Coates, G. W.; Kol, M. New facets of an old ligand: titanium and zirconium complexes of phenylenediamine bis(phenolate) in lactide polymerisation catalysis. Chem. Commun. 2009, 6804-6806.

(17) (a) Thakur, K. A. M.; Kean, R. T.; Zell, M. T.; Padden, B. E.; Munson, E. J. An alternative interpretation of the HETCOR NMR spectra of poly(lactide). Chem. Commun. 1998, 1913-1914. (b) Thakur, K. A. M.; Kean, R. T.; Hall, E. S.; Kolstad, J. J.; Lindgren, T. A.; Doscotch, M. A.; Siepmann, J. I.; Munson, E. J. HighResolution ${ }^{13} \mathrm{C}$ and ${ }^{1} \mathrm{H}$ Solution NMR Study of Poly(lactide). Macromolecules 1997, 30, 2422-2428. (c) Zell, M. T.; Padden, B. E.; Paterick, A. J.; Thakur, K. A. M.; Kean, R. T.; Hillmyer, M. A.; Munson, E. J. Unambiguous Determination of the ${ }^{13} \mathrm{C}$ and ${ }^{1} \mathrm{H}$ NMR Stereosequence Assignments of Polylactide Using High-Resolution Solution NMR Spectroscopy. Macromolecules 2002, 35, 7700-7707.

(18) Ajellal, N.; Carpentier, J.-F.; Guillaume, C.; Guillaume, S. M.; Helou, M.; Poirier, V.; Sarazin, Y.; Trifonov, A. Metal-catalyzed immortal ring-opening polymerization of lactones, lactides and cyclic carbonates. Dalton Trans. 2010, 39, 8363-8376.

(19) (a) Sarazin, Y.; Poirier, V.; Roisnel, T.; Carpentier, J.-F. Discrete, Base-Free, Cationic Alkaline-Earth Complexes - Access and Catalytic Activity in the Polymerization of Lactide. Eur. J. Inorg. Chem. 2010, 2010, 3423-3428. (b) Sarazin, Y.; Liu, B.; Roisnel, T.; Maron, L.; Carpentier, J.-F. Discrete, Solvent-Free Alkaline-Earth Metal Cations: Metal-Fluorine Interactions and ROP Catalytic Activity. J. Am. Chem. Soc. 2011, 133, 9069-9087. (c) Normand, M.; Dorcet, V.; Kirillov, E.; Carpentier, J.-F. \{Phenoxy-imine\}aluminum versus -indium Complexes for the Immortal ROP of Lactide: Different Stereocontrol, Different Mechanisms. Organometallics 2013, 32, 1694-1709.

(20) Pons, M.; Millet, O. Dynamic NMR studies of supramolecular complexes. Prog. Nucl. Magn. Reson. Spectrosc. 2001, 38, 267-281.

(21) Biela, T.; Duda, A.; Penczek, S. Control of Mn, Mw/Mn, endgroups, and kinetics in living polymerization of cyclic esters. Macromol. Symp. 2002, 183, 1-10.

(22) (a) Konkol, M.; Nabika, M.; Kohno, T.; Hino, T.; Miyatake, T. Synthesis, structure and $\alpha$-olefin polymerization activity of group 4 metal complexes with [OSSO]-type bis(phenolate) ligands. J. Organomet. Chem. 2011, 696, 1792-1802. (b) Gendler, S.; Zelikoff, A. L.; Kopilov, J.; Goldberg, I.; Kol, M. Titanium and Zirconium Complexes of Robust Salophan Ligands. Coordination Chemistry and Olefin Polymerization Catalysis. J. Am. Chem. Soc. 2008, 130, 21442145.

(23) Frisch, M. J.; Trucks, G. W.; Schlegel, H. B.; Scuseria, G. E.; Robb, M. A.; Cheeseman, J. R.; Scalmani, G.; Barone, V.; Mennucci, B.; Petersson, G. A.; Nakatsuji, H.; Caricato, M.; Li, X.; Hratchian, H. P.; Izmaylov, A. F.; Bloino, J.; Zheng, G.; Sonnenberg, J. L.; Hada, M.; Ehara, M.; Toyota, K.; Fukuda, R.; Hasegawa, J.; Ishida, M.; Nakajima, T.; Honda, Y.; Kitao, O.; Nakai, H.; Vreven, T.; Montgomery, J. A., Jr.; Peralta, J. E.; Ogliaro, F.; Bearpark, M.; Heyd, J. J.; Brothers, E.; Kudin, K. N.; Staroverov, V. N.; Kobayashi, R.; Normand, J.; Raghavachari, K.; Rendell, A.; Burant, J. C.; Iyengar, S. S.; Tomasi, J.; Cossi, M.; Rega, N.; Millam, J. M.; Klene, M.; Knox, J. E.; Cross, J. B.; Bakken, V.; Adamo, C.; Jaramillo, J.; Gomperts, R.; Stratmann, R. E.; Yazyev, O.; Austin, A. J.; Cammi, R.; Pomelli, C.; Ochterski, J. W.; Martin, R. L.; Morokuma, K.; Zakrzewski, V. G.; Voth, G. A.; Salvador, P.; Dannenberg, J. J.; Dapprich, S.; Daniels, A. D.; Farkas, O.; Foresman, J. B.; Ortiz, J. V.; Cioslowski, J.; Fox, D. J. Gaussian 09, revision A.02; Gaussian, Inc., Wallingford, CT, 2009.

(24) (a) Becke, A. D. Density-functional exchange-energy approximation with correct asymptotic behavior. Phys. Rev. A: At., Mol., Opt. Phys. 1988, 38, 3098-3100. (b) Perdew, J. P. Density-functional approximation for the correlation energy of the inhomogeneous electron gas. Phys. Rev. B: Condens. Matter Mater. Phys. 1986, 33, 8822-8824. (c) Perdew, J. P. Erratum: Density-functional approximation for the correlation energy of the inhomogeneous electron gas. Phys. Rev. B: Condens. Matter Mater. Phys. 1986, 34, 7406-7406.

(25) Hay, P. J.; Wadt, W. R. Ab initio effective core potentials for molecular calculations. Potentials for the transition metal atoms Sc to Hg. J. Chem. Phys. 1985, 82, 270-283.

(26) Legault, C. Y. CYLview, v1.0b; Université de Sherbrooke, 2009; http://www.cylview.org.

(27) SMART \& SAINT Software Reference Manuals, version 5.051 (Windows NT Version); Bruker Analytical X-ray Instruments Inc.: Madison, WI, 1998.

(28) Sheldrick, G. M. SADABS, Program for empirical absorption correction; University of Göttingen, Göttingen, Germany, 1996.

(29) Burla, M. C.; Caliandro, R.; Camalli, M.; Carrozzini, B.; Cascarano, G. L.; De Caro, L.; Giacovazzo, C.; Polidori, G.; Spagna, R. SIR2004: an improved tool for crystal structure determination and refinement. J. Appl. Crystallogr. 2005, 38, 381-388.

(30) Sheldrick, G. M. SHELXTLplus (Windows NT Version) Structure Determination Package, Version 5.1; Bruker Analytical X-ray Instruments Inc., Madison, WI, USA, 1998. 